\title{
Article \\ Style Recognition of Door God Paintings by Hypothesis Testing for Texture Features of Painting Patterns
}

\author{
Tung-Ching Su *, Tsung-Chiang Wu, Ming-Hung Wun and Cheng-Wei Wang
}

check for updates

Citation: Su, T.-C.; Wu, T.-C.; Wun, M.-H.; Wang, C.-W. Style Recognition of Door God Paintings by Hypothesis Testing for Texture Features of Painting Patterns. Appl. Sci. 2022, 12, 2637. https://doi.org/10.3390/ app12052637

Academic Editor: Asterios Bakolas

Received: 16 February 2022

Accepted: 1 March 2022

Published: 3 March 2022

Publisher's Note: MDPI stays neutral with regard to jurisdictional claims in published maps and institutional affiliations.

Copyright: (C) 2022 by the authors. Licensee MDPI, Basel, Switzerland. This article is an open access article distributed under the terms and conditions of the Creative Commons Attribution (CC BY) license (https:/ / creativecommons.org/licenses/by/ $4.0 /)$.

\author{
Department of Civil Engineering and Engineering Management, National Quemoy University, \\ Kinmen 89250, Taiwan; tsung_chiang@nqu.edu.tw (T.-C.W.); ji394su3love20@gmail.com (M.-H.W.); \\ joswawagiga@gmail.com (C.-W.W.) \\ * Correspondence: spcyj@nqu.edu.tw
}

\begin{abstract}
Many studies in the literature have presented multiple remote sensing techniques for defect inspection of paintings. At present, however, papers on defect inspection and restoration of oriental architectural arts - such as door god paintings-are still rare. If an aged and damaged door god painting needs a restoration, then following the style and treatment skill of the original artist as much as possible is important for the restoration. Unfortunately, it is usually difficult to access the original artists for some of the aged door god paintings. This paper considers the texture features of auspicious patterns of armors on warrior door gods as useful information to recognize styles of door god paintings by unknown artists. First, a two-level two-dimensional discrete wavelet transform coupled with co-occurrence matrix calculation was adopted to analyze the texture features, based on the descriptors of angular second moment (ASM), entropy (ENT), contrast (CON), homogeneity (HOM), dissimilarity (DIS), correlation (COR), and cluster tendency (CLU), in the four orientations of $0^{\circ}$ (horizontal), $45^{\circ}$ (vertical), and $90^{\circ}$ and $135^{\circ}$ (double diagonal). Second, a two-tailed $t$-test based on the analyzed texture features was introduced into the hypothesis testing for demonstrating the master and apprentice relationships between the surveyed artists, and for recognizing the door god painting styles of unknown artists as well. The experimental results show that the proposed method effectively describes the texture features of the auspicious patterns of the surveyed door god paintings, and is able to determine the useful co-occurrence features for recognizing unknown artists' painting styles.
\end{abstract}

Keywords: door god paintings; texture features; discrete wavelet transform; two-tailed $t$-test; painting style recognition

\section{Introduction}

Door god paintings are frequently seen on the gates of traditional residences or temples, and belong to one kind of Chinese architectural artworks (see Figure 1 [1]). Because of Chinese people's worship of animism in ancient times, some of the door god characters are imaginary. Today, there are several pairs of door gods representing faith in home safety and evil avoidance. The noun "door god" can be seen in the period as early as before the Qin Dynasty [2]. Essentially, the door god characters can be separated into two categories: warrior, and civil official. The greatest difference between warriors and civil officials is that a set of armor is necessary for a warrior, but unnecessary for a civil official.

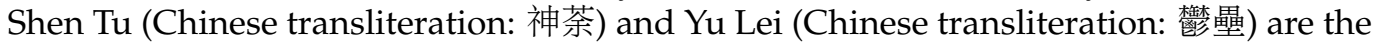
earliest warrior door gods and prevailed in the Han Dynasty [3]. In addition to Shen Tu and Yu Lei, Chin Shu Pao (Chinese transliteration: 秦叔寶) and Yu Chih Kung (Chinese transliteration: 尉遲恭) are also frequently seen warrior door gods in the temples of Taiwan. Several auspicious patterns-such as lock chain, turtle back, fish scales, flowers, clouds, and the Chinese characters of “回” and “文” (see Figure 2)—have been adopted to decorate warriors' armor. For each of the above auspicious patterns, the displayed texture features 
may be different due to the creativity of different artists. The different texture features mean that every artist has his/her own unique painting style via his/her special treatment or skill with door god paintings [4].

Any famous door god painting generally has a long history, but that long history may result in the impossibility of identifying the original artist. Additionally, door god paintings use residence or temple gates as their support materials, and so the placed locations of door god paintings belong to a semi-outdoor environment, where door god paintings are apt to suffer as a result of climate factors-such as temperature, relative humidity, and wind-or human factors, such as ritual activities and inadvertent collisions. Hence, the conservation and maintenance of door god paintings are more challenging than for other paintings or artworks collected in a well-controlled, indoor environment, such as an art gallery or museum. When restoring an aged and damaged door god painting, the treatment skill and the procedure must follow its original style as best as possible in order to preserve the unique style of the door god painting. In case of the original artist being unknown, the original style cannot be correctly followed by the painting restoration.

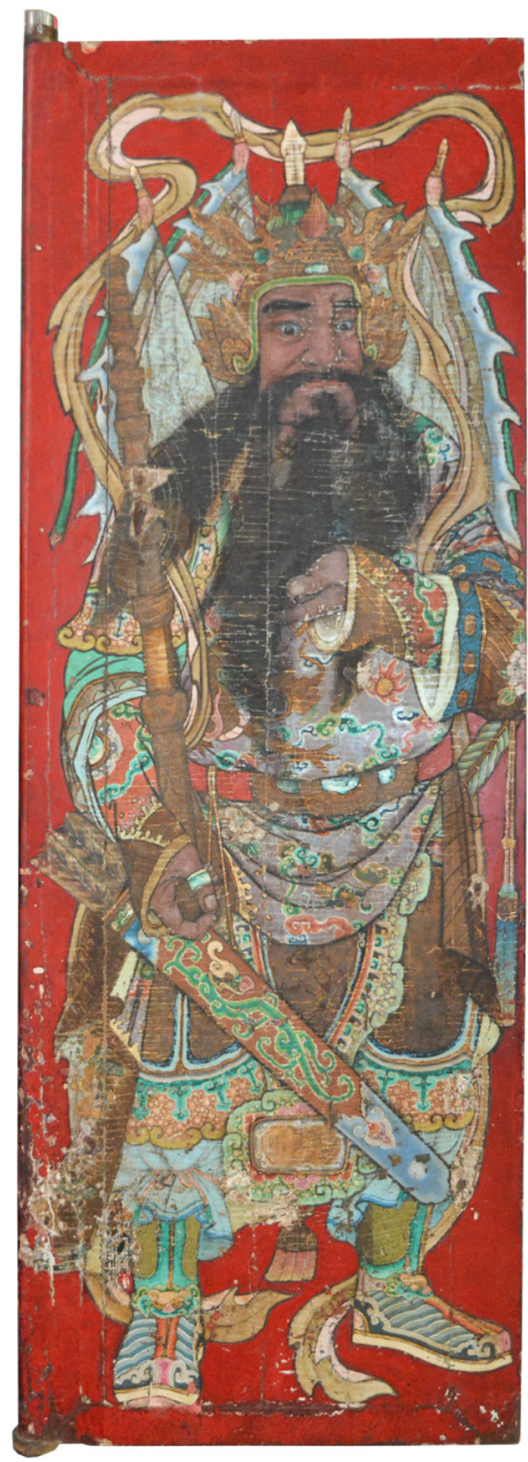

(a)

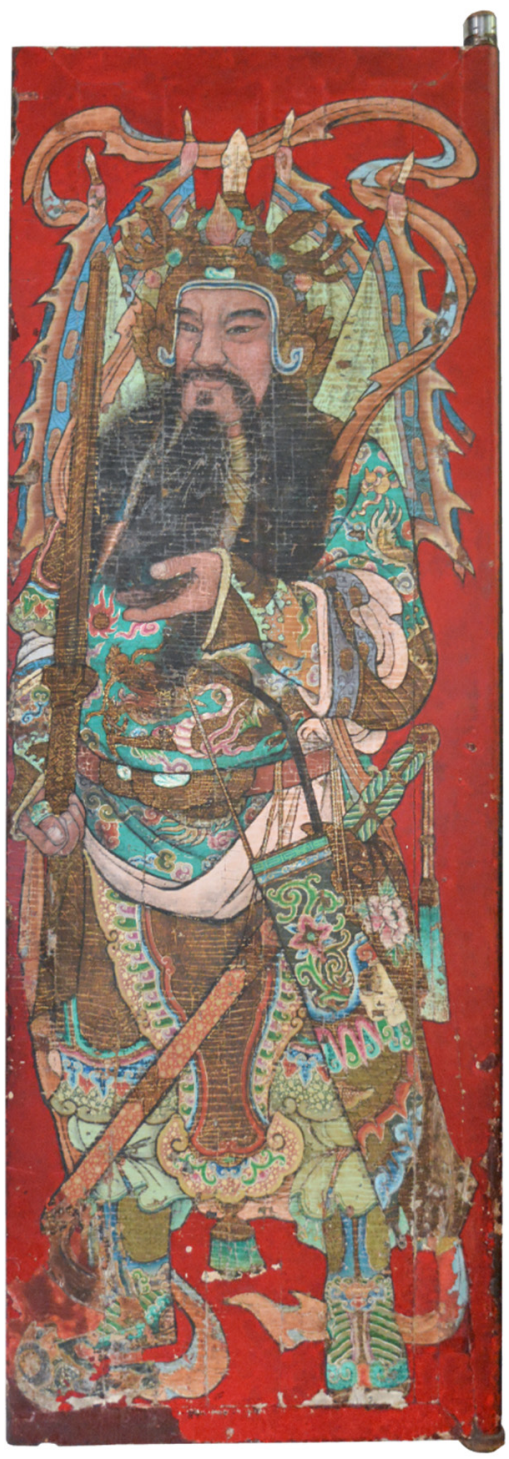

(b)

Figure 1. A pair of door god paintings: (a) Yu Chih Kung (Chinese transliteration: 尉遲恭): warrior on the left door; (b) Chin Shu Pao (Chinese transliteration: 秦叔寶): warrior on the right door [1]. 


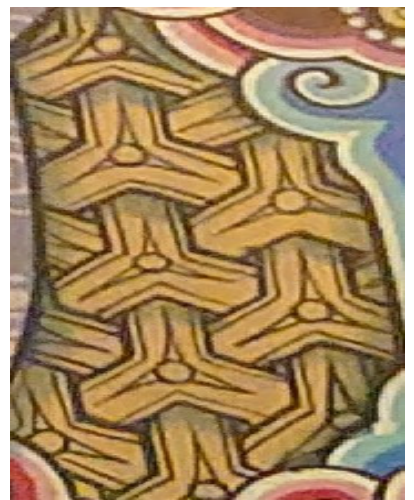

(a)

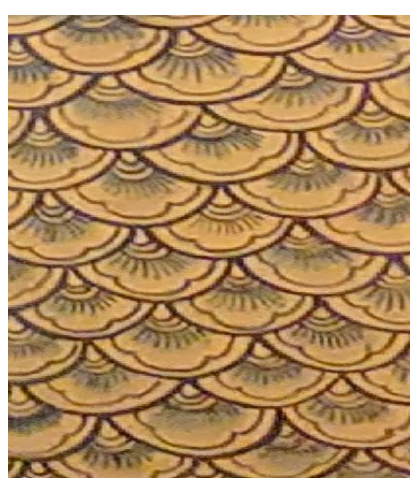

(c)

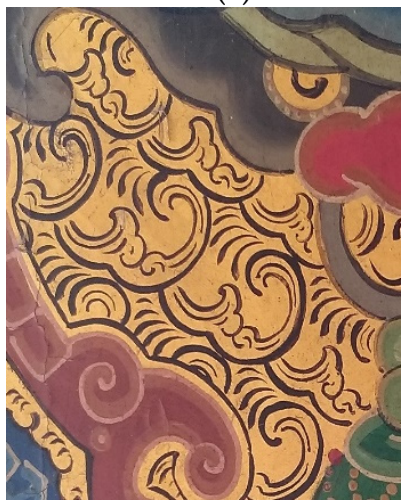

(e)

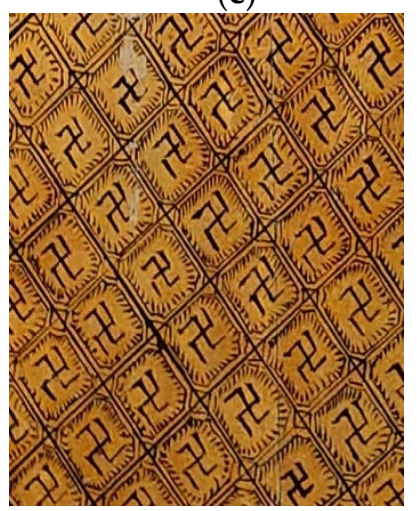

(g)

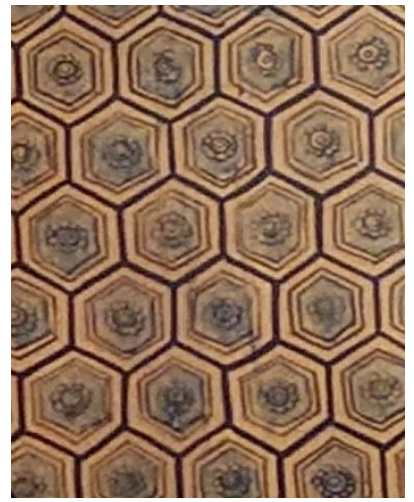

(b)

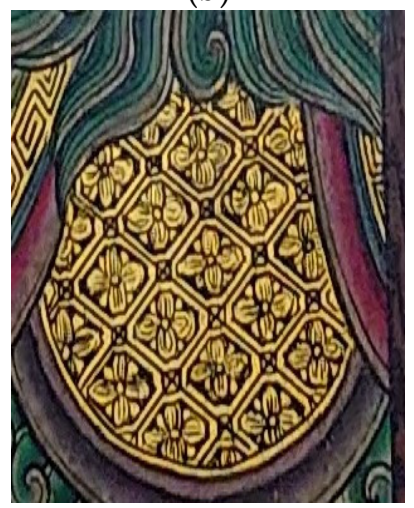

(d)

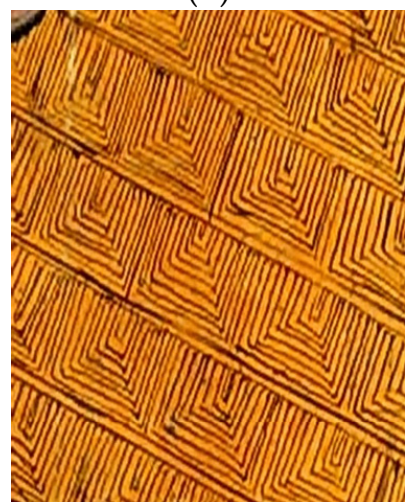

(f)

Figure 2. Example images of auspicious patterns on paintings of warriors' armor: (a) lock chain pattern; (b) turtle back pattern; (c) fish scales pattern; (d) flowers pattern; (e) clouds pattern; (f) Chinese character pattern: “回”; (g) Chinese character pattern: “艺”. 


\section{Research Aim}

The types of deterioration of door god paintings usually include lifting, cracks, shrinkage, atomization, chalking, etc. As far as we know, the current literature discussing restorations of door god paintings is quite scarce. Related image processing methods have also demonstrated their effectiveness in artwork defect detection by providing useful information for artwork restoration [5-7]. This paper's main contributions are as follows: First, to apply an image-processing-based texture analysis method to extract the texture features from the acquired auspicious pattern images. Second, hypothesis testing is implemented on the texture feature dataset to see the similarity of the auspicious patterns between the surveyed artists, and to demonstrate the master and apprentice relationship as well. Finally, hypothesis testing also is applied to the texture feature dataset to see to which painting style(s) among the surveyed artists the door god painting style(s) of the unknown artist(s) are the closest. In this way, a door god painting restoration can retain its originality as much as possible.

\section{Backgrounds}

\subsection{Artists of Door God Paintings in Taiwan}

Since around the 1960s, there have been certain famous artists who created door god paintings for traditional residences or temples in Taiwan. However, most of these famous artists are now deceased, and so their created door god paintings are regularly restored by their apprentices, some of whom are even members of the famous artists family. For instance, the two famous artists of door god paintings-Yu-Feng Chen (Chinese transliteration: 陳玉峰, 1900-1964) and Chun-Yuan Pan (Chinese transliteration: 潘春源, 1891-1972) —were both apprentices to an artist from Quanzhou, Fujian, China, and most of their door god paintings are distributed over temples in southern Taiwan. Shou-Yi Chen (Chinese transliteration: 陳壽彝, 1934-2012, the eldest son of Yu-Feng Chen) and his cousin, Tsao-Ju Tsai (Chinese transliteration: 蔡草如, 1919-2007), were both apprentices of door god painting to Yu-Feng Chen. Among the door god paintings of Yu-Feng Chen, Shou-Yi Chen, and Tsao-Ju Tsai, there is a special painting style belonging to their family genre. Similarly, Chun-Yuan Pan, Li-Shui Pan (Chinese transliteration: 潘麗水, 1914-1995, the son of Chun-Yuan Pan), and Yueh-Hsiung Pan (Chinese transliteration: 潘岳雄, 1943-present, the eldest son of Li-Shui Pan) also created door god paintings with a special painting style belonging to their family genre. Consequently, a mentorship genealogy concerning the creation of door god paintings in southern Taiwan can be established. As for artists in other areas of Taiwan, Hung [2] established a mentorship genealogy for a famous artist in Hsinchu, Taiwan, and compiled a list of the door god paintings created by the artist and his apprentices.

There have been a few cases of door god painting restoration in Taiwan in the past. In 1968, S.-Y. Chen cooperated with two other artists to refurbish aged door god paintings of the Qingshui Zushi (Divine Ancestor) Temple in New Taipei City, Taiwan [4]. Another artist, Lien-Cheng Hsu (Chinese transliteration: 許連成, 1919-2002), created door god paintings for a historic temple in northern Taiwan in 1975, and Hsu's door god paintings were refurbished in 1989 by Chia-Cheng Liu (Chinese transliteration: 劉家正, 1955-present). In fact, C.-C. Liu refurbished many of Hsu's door god paintings, but Liu's painting style belongs to the family genre of Pan rather than $\mathrm{Hsu}$, and so there is a little controversy about the restoration approach.

The original artists of the door god paintings in Taiwan can almost always be identified but, unfortunately, in Kinmen and Penghu — which are the outlying islands of Taiwan - the original artists of door god paintings are mostly difficult to ascertain. Along with the immigration of ancestors from southern Fujian (China) to Taiwan, Kinmen and Penghu were selected as the relay stops. Therefore, there certainly should be some kind of master and apprentice relationships between the artists in southern Fujian and Taiwan, including the outlying islands. 


\subsection{Texture Feature Analysis for Paintings}

An image showing a frequency of tonal change, such as zebra crossings and knitting, can be regarded as one with texture features [8]. Similarly, an auspicious pattern image also shows the frequency of tonal change. Several studies in the literature have discussed the applications of texture feature analysis to painting restoration [9-11], painting classification by artistic genre [12-14], painting style recognition [15,16], and raw material investigation [11,17]. Cai and Siegel [9] explored two texture features-energy (or homogeneity) and entropy (or disorderliness) - to model the visual appearance of paintings before and after surface varnishing. Based on a calculation of the gray-level co-occurrence matrix (GLCM), energy and entropy demonstrated that they are sensitive to the effect of varnishing-especially as entropy shows the increase in a painting's contrast by varnishing. The statistic calculation of GLCMs is a common approach, and has been used to extract texture features for the classification of traditional Chinese paintings based on the painters [18].

Wavelet-based analysis, where multiscale and multiorientation image decomposition is performed, has been applied to a collection of high-resolution digital scans of drawings or paintings to describe the painting characteristics [19]. Cetinic and Grgic [20] introduced various classifiers into automated painter recognition based on the texture features extracted by GLCM and discrete wavelet transforms (DWTs). Undoubtedly, the statistical properties of wavelet coefficients have demonstrated that they are successful in the stylistic analysis of paintings [21,22]. Referring to related research [23,24], the process of texture feature extraction first conducts image decomposition using DWT to obtain sub-band images that are multiscale and multiorientation. Secondly, GLCMs are generated from sub-band images, and finally the texture descriptors-such as energy, entropy, contrast, correlation, and others-are calculated from GLCMs.

\section{Research Material}

Based on the investigations of Lee [25] and Kang [26] on door god paintings in Taiwan, some of their investigated temples and other temples in Taiwan were selected as the study sites, and smartphones (model ASUS_Z01HDA or Sony_J9110) were used to acquire the auspicious pattern images. In total, 52 temples were visited and 453 auspicious pattern images were acquired (see the zip folder in the Supplementary Materials). Table 1 lists the number of acquired auspicious pattern images, which involve fish scales, lock chain, turtle back, and “回" patterns by the 31 artists. Among the four auspicious patterns, lock chain and fish scales are the most common patterns adopted in door god paintings, and so they have a much greater number of acquired images than the others. Moreover, the stronger the artist's reputation, the greater the number of auspicious pattern images acquired.

In addition to the 453 auspicious pattern images of the surveyed artists, we also acquired 12 auspicious pattern images of unknown artists from temples in Kinmen for the study of painting style recognition. In order to avoid blurred imaging of the door god paintings, support of the smartphones by a tripod instrument instead of a handheld approach was necessary. Considering the different sizes of the door god paintings, the appropriate instrument height and object distance had to be determined by trial and error during the imaging process. Most of the trial and error results in the field indicate that the appropriate instrument height and object distance are $\sim 1.5 \mathrm{~m}$ and $1-2 \mathrm{~m}$, respectively. Because the door god paintings are located in semi-outdoor environments, sometimes the imaging process suffers as a result of the structures of the temples, the azimuths of sunshine, or the weather, leading to an inappropriate illuminated image. An inappropriate illumination will result in an image with low quality in contrast and brightness. The f-stop numbers (apertures) of the ASUS_Z01HDA and Sony_J9110 are $f / 1.7$ and $f / 1.6$ ( $f$ : lens focal length), respectively. Thus, an automated adjustment of lens focal length was adopted in order to acquire the auspicious pattern images with appropriate contrast and brightness. 
Table 1. Numbers of auspicious pattern images, with their corresponding artists.

\begin{tabular}{|c|c|c|c|c|c|}
\hline \multirow{2}{*}{ Artist } & \multicolumn{4}{|c|}{ Auspicious Pattern } & \multirow{2}{*}{ Total } \\
\hline & Fish Scales & Lock Chain & Turtle Back & “回” & \\
\hline Lee, H.-C. (李漢卿) & 6 & - & - & - & 6 \\
\hline Wang, H.-H. \& Hung, C.-S. (王錫河 \& 洪純宋) & 5 & - & - & - & 5 \\
\hline Lin, C.-H. (林中信) & 8 & 3 & - & - & 11 \\
\hline Chang, C.-K. (張劍光) & 5 & 2 & - & - & 7 \\
\hline Yu, C.-H. (游景賢) & 3 & 3 & - & - & 6 \\
\hline Liu, C.-C. (劉家正) & 14 & 16 & - & - & 30 \\
\hline Pan, Y.-H. (潘岳雄) & 12 & 3 & - & - & 15 \\
\hline Mei, Y.-S. (梅月杉) & 4 & 2 & - & - & 6 \\
\hline Hsu, M.-Y. (許明義) & 6 & 5 & - & - & 11 \\
\hline Tsai, M.-H. (蔡孟學) & 4 & 1 & - & - & 5 \\
\hline $\begin{array}{l}\text { Tsai, H.-Y. \& Tsai, W.-C. } \\
\text { (蔡海永 \& 蔡文傑) }\end{array}$ & 3 & 4 & - & - & 7 \\
\hline Yen, W.-P. (顔文伯) & 4 & 2 & - & - & 6 \\
\hline Su, T.-F. (蘇天福) & 8 & 10 & - & - & 18 \\
\hline Chung, Y.-S. (鐘銀樹) & 4 & 1 & - & - & 5 \\
\hline Cho, F.-T. (卓福田) & 2 & - & - & - & 2 \\
\hline Chen, C.-S. (陳秋山) & 5 & 1 & - & - & 6 \\
\hline Wang, H.-H. (王錫河) & 6 & 5 & 1 & - & 12 \\
\hline Chu, Y.-L. (朱銀) & 5 & 4 & 1 & - & 10 \\
\hline Lu, S.-W. (呂石旺) & 4 & 3 & 2 & - & 9 \\
\hline Kuo, F.-T. (郭佛賜) & 12 & 7 & 4 & - & 23 \\
\hline Chen, Y.-C. (陳陽春) & 11 & 11 & 4 & - & 26 \\
\hline Pan, L.-S. (潘麗水) & 67 & 35 & 2 & 3 & 107 \\
\hline Chuang, W.-N. (莊武男) & 5 & 11 & 1 & - & 17 \\
\hline Wang, J.-Y. (王瑞瑜) & 2 & 4 & - & 2 & 8 \\
\hline Dragon (鹿港小龍) & 1 & 4 & - & 1 & 6 \\
\hline Chang, H.-L. (張火爐) & 2 & 3 & - & 3 & 8 \\
\hline Huang, M.-S. (黃名樹) & 1 & 2 & - & 1 & 4 \\
\hline Tsai, L.-C. (蔡龍進) & 15 & 5 & - & - & 20 \\
\hline Hsu, L.-C. (許連成) & 8 & - & 1 & 5 & 14 \\
\hline Chen, S.-Y. (陳壽彝) & 13 & 20 & 6 & 4 & 43 \\
\hline Total & 245 & 167 & 22 & 19 & 453 \\
\hline
\end{tabular}

\section{Methodology}

\subsection{Texture Feature Extraction}

Figure 3 shows a diagram of the texture feature extraction proposed in this paper. Before performing the 2-level 2-dimensional (2D) DWT, each RGB-wise auspicious pattern image is transformed into a grayscale one. In other words, the color information is not taken into consideration for our DWT operation. After the 2-level 2D DWT, an approximation image and three detailed images in horizontal $\left(0^{\circ}\right)$, vertical $\left(90^{\circ}\right)$, and diagonal $\left(45^{\circ}\right.$ or $135^{\circ}$ ) orientations are derived. Based on the three detailed images, the GLCMs in the 4 orientations are calculated. Hereafter, each GLCM calculates the co-occurrence features, consisting of angular second moment (ASM), entropy (ENT), contrast (CON), homogeneity $(\mathrm{HOM})$, dissimilarity (DIS), correlation (COR), and cluster tendency (CLU). In this research, the co-occurrence features in a certain orientation can be expressed as a $1 \times 7$ vector, and so the co-occurrence features in the 4 orientations are finally integrated into a $4 \times 7$ matrix. 


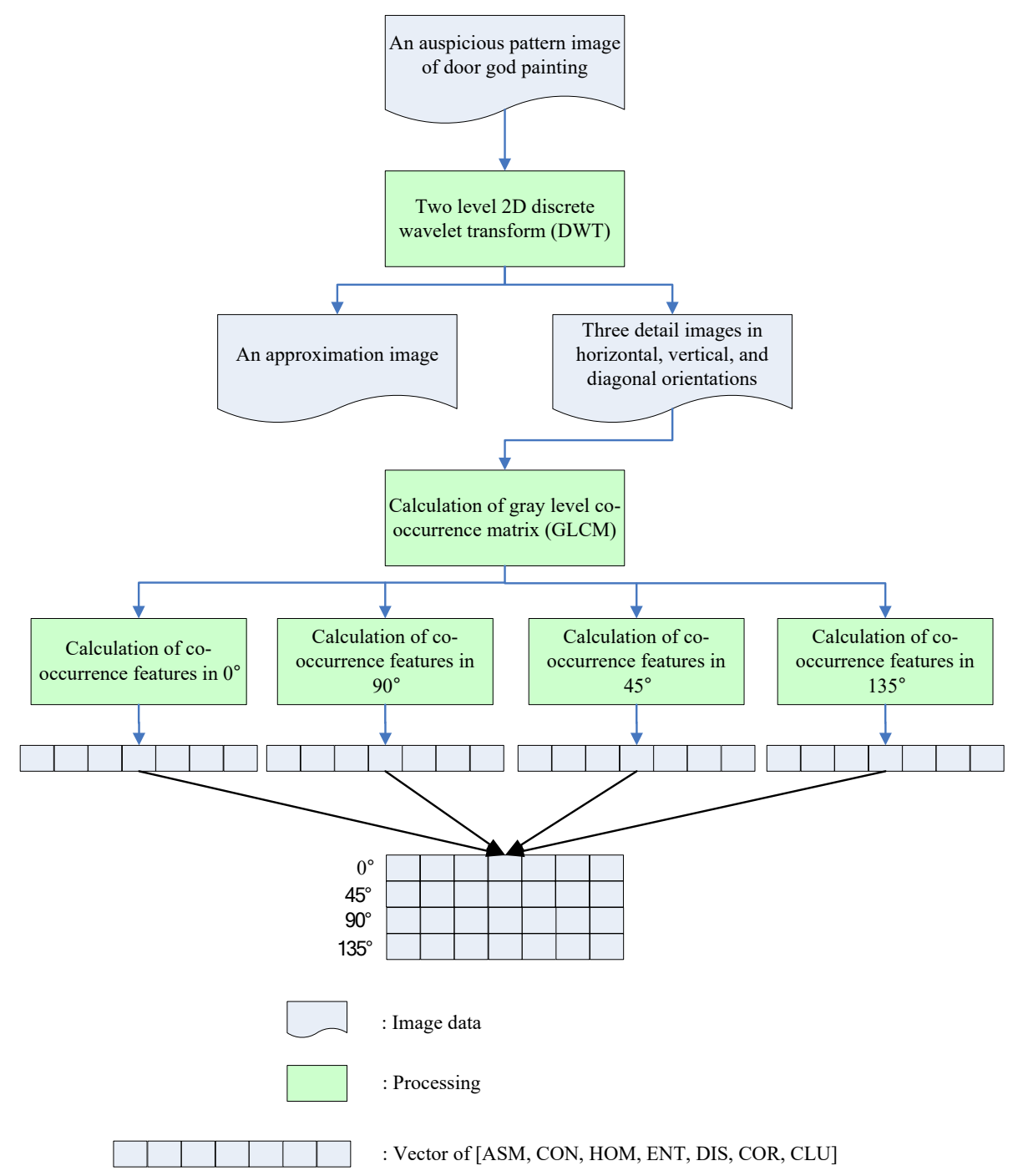

Figure 3. Scheme of texture feature extraction from auspicious pattern imagery.

\subsubsection{Two-Level 2D DWT}

Wavelet transform (WT) is a linear transform developed from Fourier transform, where the basic functions are sinusoids, but the wavelet functions vary with frequency and limit duration, thus offering better resolutions along the frequency scale $[27,28]$. In the beginning, the development of WT was for signal processing, but not for image processing, until Daubechies and Mallat provided the discretization of WT and established the connection between WT and the multiresolution theory, respectively. This paper regards an auspicious pattern image as the change in a discrete signal along a 2D scale. A 2D DWT can decompose the auspicious pattern image into many scales, which range from the roughest scale to the finest [29-31]. Through a decomposition of 2D DWT, which is implemented by consecutive low-pass ( $\mathrm{L}$ ) and high-pass $(\mathrm{H})$ filtering through one-dimensional convolution, the auspicious pattern image $\mathrm{I}(m, n)$ can be divided into sub-band images, including an approximation image (LL) and three detailed images in horizontal (HL), vertical (LH), and diagonal (HH) orientations [28]. The parameters of $m$ and $n$ denote the number of pixels of the image in the row and column directions, respectively.

The approximation image (LL) can be further decomposed in the next level to obtain the images of LL, HL, $\mathrm{LH}$, and $\mathrm{HH}$, with the sizes of $(m / 2, n / 2)$. For the decomposition of each level, the alternative convolutions of the approximation image and the low-pass or high-pass filters in the column or row directions are operated using a downsampling function by 2 . Thus, the $2 \mathrm{D}$ DWT finally produces the pyramid representations of the 
sub-band images, which occupy the same amount of storage as the original auspicious pattern image [32].

Several studies in the literature indicate that the 2-level 2D DWT (i.e., 2D DWT in the second level) can robustly extract the details of the image texture features from the original images $[23,24,28,33]$. After decomposition in the second level, the 7 sub-band images, including 6 detailed images (HL1, LH1, HH1, HL2, LH2, and HH2) and one approximation image (LL2), are obtained. The indices of " 1 " and " 2 " signify the first and second levels, respectively. Among the above 6 detailed images, HL2, LH2, and HH2 were chosen to calculate the paper's GLCMs.

\subsubsection{Calculation of the Gray-Level Co-Occurrence Matrix (GLCM)}

A GLCM is a one-dimensional square matrix, where each element in the row (i) and column $(j)$ directions records a relative occurrence frequency $\left(M_{i j}\right)$ of a pair of pixels with the same element value, separated by a certain pixel distance $(D)$ in one orientation $(\theta)[23,28]$. Figure 4 shows an illustration of GLCM production at different orientations and pixel distances for a pixel of interest in the square matrix, along with an example of statistics for $M_{i j}$ at $90^{\circ}$ (vertical direction) and one pixel distance. Figure $4 \mathrm{~b}$ shows the GLCM of an example detailed image, where the image size is 7-by-7 (but not limited to square) and the number of gray levels is 8 . In the GLCM, the element $(3,0)$ has a value of 1 , because there is only one instance in the example detailed image where the vertically adjacent pixels $(2$, 1 ) and $(1,1)$ have gray-level values of 3 and 0 , respectively.

(a)

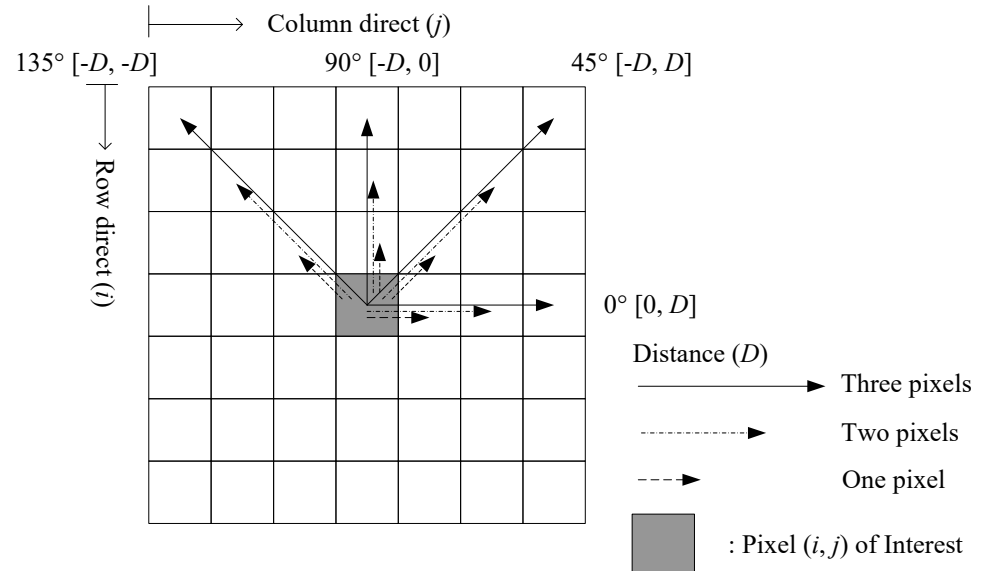

(b)

\begin{tabular}{|l|l|l|l|l|l|l|}
\hline 0 & 6 & 6 & 2 & 6 & 2 & 6 \\
\hline 3 & 6 & 0 & 3 & 1 & 6 & 3 \\
\hline 6 & 1 & 4 & 4 & 6 & 1 & 6 \\
\hline 1 & 6 & 2 & 3 & 0 & 6 & 2 \\
\hline 4 & 3 & 4 & 4 & 4 & 1 & 3 \\
\hline 4 & 1 & 0 & 2 & 5 & 6 & 0 \\
\hline 2 & 5 & 5 & 6 & 4 & 2 & 5 \\
\hline \multicolumn{7}{|c|}{ Digital image }
\end{tabular}

\begin{tabular}{cc|c|c|c|c|c|c|c|}
$j$ & $j$ & 0 & 1 & 2 & 3 & 4 & 5 & 6 \\
\cline { 2 - 8 } & 0 & 0 & 0 & 0 & 1 & 1 & 0 & 2 \\
\cline { 2 - 8 } & 1 & 0 & 0 & 0 & 1 & 0 & 0 & 5 \\
\cline { 2 - 8 } 2 & 0 & 0 & 0 & 0 & 3 & 0 & 2 \\
\cline { 2 - 8 } 3 & 1 & 0 & 2 & 0 & 1 & 0 & 2 \\
\cline { 2 - 8 } 4 & 1 & 1 & 1 & 2 & 1 & 1 & 0 \\
\cline { 2 - 8 } 5 & 2 & 1 & 0 & 0 & 1 & 0 & 0 \\
\cline { 2 - 8 } & 6 & 0 & 4 & 2 & 2 & 0 & 0 & 1 \\
\cline { 2 - 7 } & \multicolumn{7}{|c|}{ GLCM }
\end{tabular}

Figure 4. Illustration of GLCM production: (a) A pair of pixels with the same element value separated by the different pixel distances in 4 orientations. (b) Relative occurrence frequency recording of gray levels of digital images, using a GLCM with $D=1$ and $\theta=90^{\circ}$. 
Except for the four necessary orientations of $0^{\circ}, 45^{\circ}, 90^{\circ}$, and $135^{\circ}$, several studies have indicated that the different pixel distances $(D)$ have a great influence on the accuracy of GLCM-based texture description, and demonstrated that one pixel distance $(D=1)$ can lead to better accuracy of the feature extractions [23,34]. This paper introduces an adjacent distance of bordering on pixels instead of striding over pixels into the calculation of the GLCMs.

\subsubsection{Calculation of Co-Occurrence Features}

The GLCMs obtained from the detailed images of HL2 and LH2 further calculate the co-occurrence features in $0^{\circ}$ and $90^{\circ}$, respectively. Both of the GLCMs in $45^{\circ}$ and $135^{\circ}$ obtained from the detailed image of $\mathrm{HH} 2$ further calculate the co-occurrence features in the double-diagonal orientations. The 7 aforementioned co-occurrence features can be obtained using the following texture descriptors:

Angular Second Moment (ASM): The uniformity of distribution of the gray level in an auspicious pattern image can be represented thus [35]. The texture descriptor of ASM is expressed as follows:

$$
\sum_{i=1}^{n} \sum_{j=1}^{n} P_{i j}^{2}
$$

The value of ASM ranges from $1 / n^{2}$ to 1 . When the value is 1 , it means a constant image. Here, $P_{i j}$ is calculated as $\frac{M_{i j}}{\sum_{i=1}^{n} \sum_{j=1}^{n} M_{i j}}$.

Entropy (ENT): A statistical measure of randomness determines the textural interference in an auspicious pattern image $[24,35]$. The texture descriptor of ENT is obtained as follows:

$$
-\sum_{i=1}^{n} \sum_{j=1}^{n} P_{i j} \cdot \log _{10}^{P_{i j}}
$$

The larger the ENT value, the higher the textural complexity of the auspicious pattern. Thus, there should be a highly negative correlation between ASM and ENT.

Contrast $(\mathrm{CON})$ : The local variations in an auspicious pattern image can be measured by this descriptor, which is calculated as follows:

$$
\sum_{i=1}^{n} \sum_{j=1}^{n}(i-j)^{2} \cdot P_{i j}
$$

The higher the CON, the higher the image contrast will be. Hence, a CON of 0 means a constant image.

Homogeneity (HOM): HOM can also be called an inverse differential moment, which measures the similarity between the distributions of elements in a GLCM and those in the diagonal GLCM [24]. The textural descriptor is defined as follows:

$$
\sum_{i=1}^{n} \sum_{j=1}^{n} \frac{P_{i j}}{1+(i-j)^{2}}
$$

The representation of HOM is contrary to that of CON-the higher the HOM, the lower the image contrast (or the more the image homogeneity) will be.

Dissimilarity (DIS): The degree of dissimilarity of the gray levels in an auspicious pattern image is now measured. DIS is very sensitive to the arrangement of gray-level values or tones in an imagery space, and is expressed as follows:

$$
\sum_{i=1}^{n} \sum_{j=1}^{n}|i-j| P_{i j}
$$

A higher DIS value means a greater dissimilarity of gray levels in the image. 
Correlation (COR): The spatial dependencies between the image pixels can be defined [24] to indicate the textural directionalities of the auspicious patterns [36] by this textural descriptor, which is calculated as follows:

$$
\frac{\sum_{i=1}^{n} \sum_{j=1}^{n}(i \cdot j) P_{i j}-\mu_{x} \mu_{y}}{\sigma_{x} \sigma_{y}}
$$

In other words, COR is a correlation coefficient of GLCM. The higher the COR is, the greater is the spatial dependency of gray levels in a certain direction.

Cluster tendency (CLU): The degree of the textural clustering in an auspicious pattern image is measured and can be obtained as:

$$
\sum_{i=1}^{n} \sum_{j=1}^{n}\left(i-\mu_{x}+j-\mu_{y}\right)^{2} \cdot P_{i j}
$$

It should be noted that a lower CLU value means higher textural clustering. Moreover, there is an interrelationship between CLU and COR. When the values of CLU and COR are large, there will be an indefinite textural directionality or a wide distribution of gray levels. Here, $\mu_{x}, \mu_{y}, \sigma_{x}$, and $\sigma_{y}$ are calculated as follows:

$$
\left\{\begin{array}{c}
\mu_{x}=\sum_{i=1}^{n} \sum_{j=1}^{n} i \cdot P_{i j} \\
\mu_{y}=\sum_{i=1}^{n} \sum_{j=1}^{n} j \cdot P_{i j} \\
\sigma_{x}=\sqrt{\sum_{i=1}^{n} \sum_{j=1}^{n}\left(i-\mu_{x}\right)^{2} \cdot P_{i j}} \\
\sigma_{y}=\sqrt{\sum_{i=1}^{n} \sum_{j=1}^{n}\left(j-\mu_{y}\right)^{2} \cdot P_{i j}}
\end{array}\right.
$$

\subsection{Statistical Testing}

This paper adopted a two-tailed $t$-test to test the similarity between any two auspicious patterns, the similarity of an auspicious pattern between any two surveyed artists, or the similarity of an auspicious pattern between the surveyed and unknown artists. The hypotheses of the $t$-tests are described as follows:

\subsubsection{Testing for Similarity between Any Two Auspicious Patterns}

This paper aims to examine the similarities and differences between the auspicious patterns in door god paintings in Taiwan by applying hypothesis testing to the obtained co-occurrence features. As shown in to Figure 3, we calculated the co-occurrence feature values for each auspicious pattern image, which were recorded as a 4-by-7 matrix. Thus, the obtained co-occurrence feature values in a certain orientation can be arranged as an $n$-by-7 matrix, where $n$ is the number of auspicious pattern images. In the fish scales pattern, for example, the data size of its obtained co-occurrence feature values in one orientation is 245-by-7. The arrangement of the 245-by-7 matrix also means that the hypothesis testing does not consider the different painting styles between the artists. For each orientation, any 2 of the 4 auspicious patterns performed a two-tailed $t$-test, where the null $\left(\mathrm{H}_{0}\right)$ and alternative $\left(\mathrm{H}_{1}\right)$ hypotheses were expressed as follows:

$$
\left\{\begin{array}{l}
\mathrm{H}_{0}: D_{i}=D_{j} \\
\mathrm{H}_{1}: D_{i} \neq D_{j}
\end{array}\right.
$$

and $D_{i}$ and $D_{j}$ are the $n$-by-7 data matrices of the extracted co-occurrence features of auspicious patterns $i$ and $j$, respectively. Thus, there is a total of $C_{2}^{4}=6$ combinations for the two-tailed $t$-test. 


\subsubsection{Testing for Similarity of an Auspicious Pattern between Any Two Surveyed Artists}

This paper demonstrates whether any two surveyed artists have a master and apprentice relationship by applying hypothesis testing to the extracted co-occurrence features of the auspicious patterns of their door god paintings. For some artists, unfortunately, there are extremely few images accessibly acquired, resulting in a non-normal distribution for the number of tested samples. In order to control the risk of accepting a false hypothesis, both $\alpha$ and $\beta$-which are the probabilities of rejecting and accepting the null hypothesis, respectively-must be considered. For this paper, the values of $\alpha / 2=0.05$ and $\beta=0.1$ were introduced into the calculation of the minimum sample size $(\mathrm{N})$ from the National Institute of Standards and Technology [37]:

$$
\mathrm{N} \geq\left(\mathrm{t}_{1-\frac{\alpha}{2}}+\mathrm{t}_{1-\beta}\right)^{2}\left(\frac{\mathrm{s}}{\delta}\right)^{2}
$$

where s and $\delta$ denote the standard deviations of the samples and the population, respectively. In this paper, $\mathrm{s}$ is equal to $\delta$, so Equation (10) can be rewritten as $\left(\mathrm{t}_{1-\frac{\alpha}{2}}+\mathrm{t}_{1-\beta}\right)^{2}$. Considering the degrees of freedom as 30, the values of $t_{1-\frac{\alpha}{2}}$ and $t_{1-\beta}$ are 1.6973 and 1.3104, respectively; thus, the $N$ value approximates to 9.

According to the above estimation for the minimum size of samples, this paper considers the surveyed artists, from whom we can acquire more than 10 images (including 10 images) for some auspicious patterns, using a two-tailed $t$-test. Therefore, from Table 1 , only the fish scales and lock chain patterns satisfy the above condition, and there is a total of $\mathrm{C}_{2}^{n_{a}}\left(n_{a}\right.$ : number of considered artists) combinations for the two-tailed $t$-test. In this paper, the $n_{a}$ values are 7 and 6 for the fish scales and lock chain patterns, respectively. The cooccurrence features of the fish scales and lock chain patterns in an orientation are arranged as an $m$-by-7 data matrix, where $m(m \geq 10)$ is the number of acquired auspicious pattern images for a certain considered artist. Based on Equation (9), here $D_{i}$ and $D_{j}$ represent the $m$-by-7 data matrices of artists $i$ and $j$, respectively.

\subsubsection{Testing for Similarity of an Auspicious Pattern between Surveyed and Unknown Artists}

The two-tailed $t$-test was applied to the extracted co-occurrence features of the fish scales or lock chain patterns of the unknown artists' door god paintings to determine whether there was a similar painting style between the surveyed and unknown artists. Among the acquired 12 auspicious pattern images of the unknown artist(s), the number of fish scales and lock chain pattern images was half each. Hence, the sample of just 6 images is able to control the risk of accepting a false hypothesis by the two-tailed $t$-test, with $\alpha / 2=0.05, \beta=0.05$, and $\delta=1.5 \mathrm{~s}$. In the two-tailed $t$-test, an $l$-by-7 ( $l=6$ in this paper) data matrix was built for recording the co-occurrence features of the fish scales or lock chain patterns in an orientation, where $l$ is the number of acquired fish scales or lock chain pattern images for the unknown artist(s). Based on Equation (9), here $D_{i}$ and $D_{j}$ represent the $m$-by-7 and l-by-7 data matrices of surveyed artist $i$ and unknown artist $j$, respectively.

\section{Results and Discussion}

\subsection{Texture Features of Surveyed Auspicious Patterns}

The four auspicious patterns in Table 1, including fish scales, lock chain, turtle back, and “回”, were surveyed and calculated for their co-occurrence features (texture features), as shown in Figure 5. Here, each co-occurrence feature plotted in Figure 5 is a mean of all of the calculated co-occurrence features of the acquired images for the auspicious pattern. Figure 5 shows that for any auspicious pattern the co-occurrence features in the double-diagonal orientations are approximately equal. This result demonstrates that all four of the auspicious patterns have texture symmetry in the double-diagonal orientations. The co-occurrence features of the four auspicious patterns are discussed as follows: 


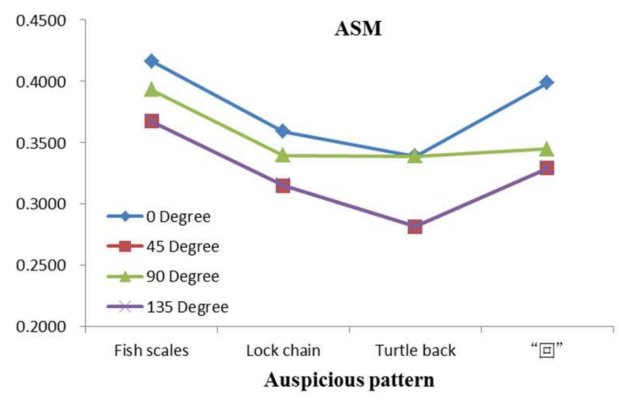

(a)

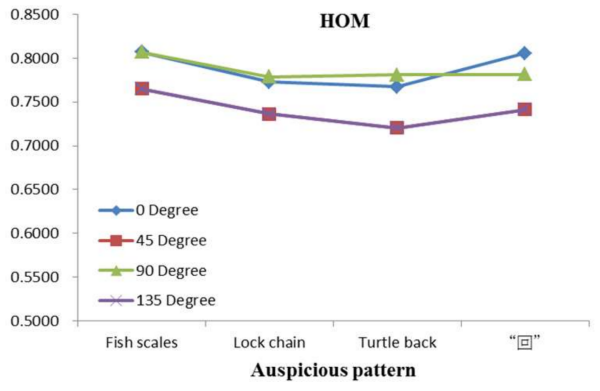

(c)

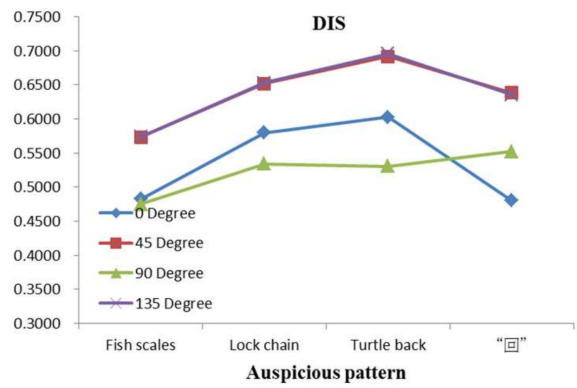

(e)

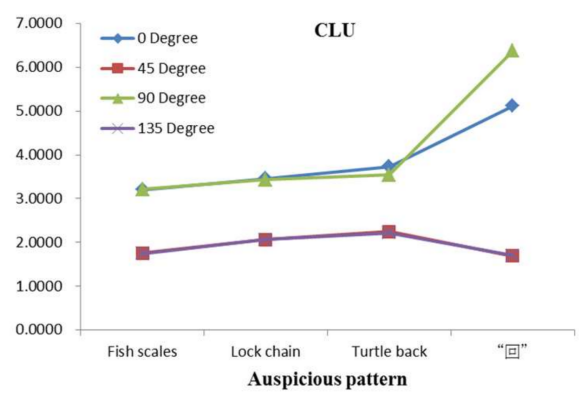

(g)

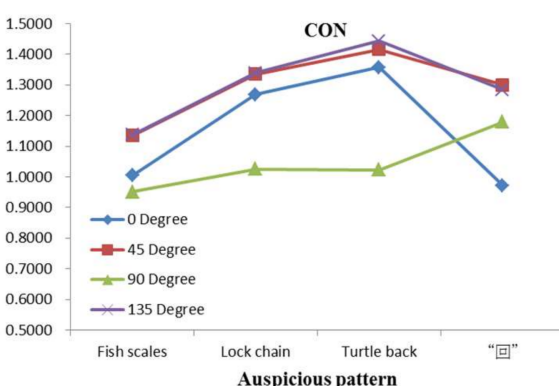

(b)

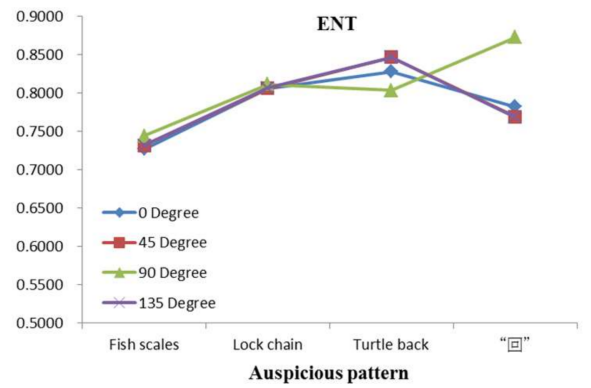

(d)

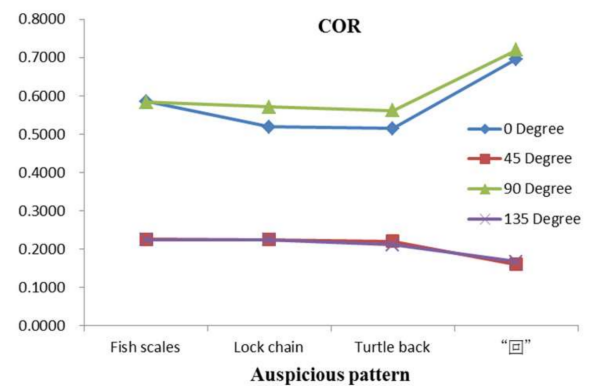

(f)

Figure 5. Texture features of auspicious pattern examples in different orientations: (a) ASM. (b) CON. (c) HOM. (d) ENT. (e) DIS. (f) COR. (g) CLU.

In ASM the fish scales and turtle back patterns obtained the highest and lowest cooccurrence feature values, respectively. This result demonstrates that the fish scales pattern images are more constant than the others. For any auspicious pattern, the distribution of gray levels in the horizontal orientation is more uniform than those in the other orientations.

In $\mathrm{CON}$, Figure $5 \mathrm{~b}$ illustrates that the imagery contrasts of the auspicious patterns in the double-diagonal orientations are higher than those in the horizontal or vertical orientations. Except for the "回" pattern, the co-occurrence feature values in the vertical orientation are lower than those in the other orientations, where the co-occurrence feature values of the turtle back pattern are the highest. Thus, compared with the other patterns, the turtle back pattern usually has the highest imagery contrast. Figure $5 b, c$ illustrate that the concave shapes of the obtained curves in HOM run contrary to the convex ones in CON. 
Due to the slightly higher HOM values of the fish scales pattern, the textural descriptor of HOM demonstrates that the fish scales pattern has a lower contrast than the other patterns. The lower imagery contrast also means a greater imagery constant.

In addition to CON and HOM, the shapes of the obtained curves between ENT and ASM are also contrary. The ENT value of the “回” pattern in the vertical orientation is clearly much larger than that of the other patterns in the different orientations. This result shows that, compared with the other patterns, the “回” pattern in the vertical orientation has the highest textural complexity. Excluding the vertical orientation, the turtle back pattern has the highest textural complexity. However, there are similar shapes of the obtained curves between CLU and COR. In COR, the values in the horizontal and vertical orientations are far higher than those in the double-diagonal orientations. Among the auspicious patterns, the "回” pattern has an extreme difference in the COR values between the horizontal or vertical orientations and the double-diagonal ones. Thus, this paper demonstrates that greater spatial dependency of gray levels in the auspicious pattern images means higher CLU values, i.e., higher textural clustering.

In DIS, Figure 5e shows that the auspicious pattern images have higher dissimilarity of the gray levels in the double-diagonal orientations than in the horizontal or vertical orientations. It is noticeable that the shapes of the obtained curves between CON and DIS are similar (see Figure 5b,e). Hence, textural analysis demonstrates that there is an interrelationship between CON and DIS for the four auspicious patterns. A higher contrast of an auspicious pattern image means a higher dissimilarity of the gray levels in the image.

\subsection{Similarity between Any Two Auspicious Patterns}

A two-tailed $t$-test was applied to the calculated co-occurrence features to see the similarity between any two of the four auspicious patterns, and the results of the six combinations are shown in Table 2. The results confirm that there is the most textural difference between the fish scales and lock chain patterns, and the most textural similarity between the lock chain and turtle back patterns. This result indicates that it is easy to distinguish the fish scales patterns from lock chain patterns, but very difficult to distinguish the lock chain patterns from turtle back patterns. In spite of that, the textures of the fish scales and lock chain patterns were sometimes confused when considering some of the textural descriptors in certain orientations, e.g., CON in the vertical orientation.

Table 2 also indicates that the fish scales and turtle back patterns in the horizontal and vertical orientations almost have a significant texture similarity. However, applying the textural descriptors of ASM, HOM, ENT, and DIS to the texture features in the doublediagonal orientations confirms that there is a significant difference between the fish scales and turtle back patterns. In other words, the four above textural descriptors in the doublediagonal orientations are useful in recognition of the fish scales and turtle back patterns. Finally, most of the textural descriptors in any orientation are inadequate to distinguish the “回” pattern from the others unless one considers the textural descriptor of COR. 
Table 2. Two-tailed $t$-test results for similarity between any two auspicious patterns.

\begin{tabular}{|c|c|c|c|c|c|c|c|c|}
\hline \multirow{2}{*}{ Tested Patterns } & \multirow{2}{*}{ Orientation } & \multicolumn{7}{|c|}{ Co-Occurrence Feature } \\
\hline & & ASM & $\mathrm{CON}$ & HOM & ENT & DIS & COR & CLU \\
\hline \multirow{4}{*}{$\begin{array}{c}\text { Fish scales } \\
\text { vs. } \\
\text { Lock chain }\end{array}$} & $0^{\circ}$ & $\mathrm{H}_{1}$ & $\mathrm{H}_{1}$ & $\mathrm{H}_{1}$ & $\mathrm{H}_{1}$ & $\mathrm{H}_{1}$ & $\mathrm{H}_{1}$ & $\mathrm{H}_{0}$ \\
\hline & $45^{\circ}$ & $\mathrm{H}_{1}$ & $\mathrm{H}_{1}$ & $\mathrm{H}_{1}$ & $\mathrm{H}_{1}$ & $\mathrm{H}_{1}$ & $\mathrm{H}_{0}$ & $\mathrm{H}_{1}$ \\
\hline & $90^{\circ}$ & $\mathrm{H}_{1}$ & $\mathrm{H}_{0}$ & $\mathrm{H}_{1}$ & $\mathrm{H}_{1}$ & $\mathrm{H}_{0}$ & $\mathrm{H}_{0}$ & $\mathrm{H}_{0}$ \\
\hline & $135^{\circ}$ & $\mathrm{H}_{1}$ & $\mathrm{H}_{1}$ & $\mathrm{H}_{1}$ & $\mathrm{H}_{1}$ & $\mathrm{H}_{1}$ & $\mathrm{H}_{0}$ & $\mathrm{H}_{1}$ \\
\hline \multirow{4}{*}{$\begin{array}{l}\text { Fish scales } \\
\text { vs. } \\
\text { Turtle back }\end{array}$} & $0^{\circ}$ & $\mathrm{H}_{1}$ & $\mathrm{H}_{0}$ & $\mathrm{H}_{0}$ & $\mathrm{H}_{0}$ & $\mathrm{H}_{0}$ & $\mathrm{H}_{0}$ & $\mathrm{H}_{0}$ \\
\hline & $45^{\circ}$ & $\mathrm{H}_{1}$ & $\mathrm{H}_{0}$ & $\mathrm{H}_{1}$ & $\mathrm{H}_{1}$ & $\mathrm{H}_{1}$ & $\mathrm{H}_{0}$ & $\mathrm{H}_{0}$ \\
\hline & $90^{\circ}$ & $\mathrm{H}_{0}$ & $\mathrm{H}_{0}$ & $\mathrm{H}_{0}$ & $\mathrm{H}_{0}$ & $\mathrm{H}_{0}$ & $\mathrm{H}_{0}$ & $\mathrm{H}_{0}$ \\
\hline & $135^{\circ}$ & $\mathrm{H}_{1}$ & $\mathrm{H}_{0}$ & $\mathrm{H}_{1}$ & $\mathrm{H}_{1}$ & $\mathrm{H}_{1}$ & $\mathrm{H}_{0}$ & $\mathrm{H}_{0}$ \\
\hline \multirow{4}{*}{$\begin{array}{c}\text { Fish scales } \\
\text { vs. } \\
\text { "回" }\end{array}$} & $0^{\circ}$ & $\mathrm{H}_{0}$ & $\mathrm{H}_{0}$ & $\mathrm{H}_{0}$ & $\mathrm{H}_{0}$ & $\mathrm{H}_{0}$ & $\mathrm{H}_{1}$ & $\mathrm{H}_{1}$ \\
\hline & $45^{\circ}$ & $\mathrm{H}_{0}$ & $\mathrm{H}_{0}$ & $\mathrm{H}_{0}$ & $\mathrm{H}_{0}$ & $\mathrm{H}_{0}$ & $\mathrm{H}_{1}$ & $\mathrm{H}_{0}$ \\
\hline & $90^{\circ}$ & $\mathrm{H}_{0}$ & $\mathrm{H}_{0}$ & $\mathrm{H}_{0}$ & $\mathrm{H}_{0}$ & $\mathrm{H}_{0}$ & $\mathrm{H}_{1}$ & $\mathrm{H}_{1}$ \\
\hline & $135^{\circ}$ & $\mathrm{H}_{0}$ & $\mathrm{H}_{0}$ & $\mathrm{H}_{0}$ & $\mathrm{H}_{0}$ & $\mathrm{H}_{0}$ & $\mathrm{H}_{1}$ & $\mathrm{H}_{0}$ \\
\hline \multirow{4}{*}{$\begin{array}{l}\text { Lock chain } \\
\text { vs. } \\
\text { Turtle back }\end{array}$} & $0^{\circ}$ & $\mathrm{H}_{0}$ & $\mathrm{H}_{0}$ & $\mathrm{H}_{0}$ & $\mathrm{H}_{0}$ & $\mathrm{H}_{0}$ & $\mathrm{H}_{0}$ & $\mathrm{H}_{0}$ \\
\hline & $45^{\circ}$ & $\mathrm{H}_{0}$ & $\mathrm{H}_{0}$ & $\mathrm{H}_{0}$ & $\mathrm{H}_{0}$ & $\mathrm{H}_{0}$ & $\mathrm{H}_{0}$ & $\mathrm{H}_{0}$ \\
\hline & $90^{\circ}$ & $\mathrm{H}_{0}$ & $\mathrm{H}_{0}$ & $\mathrm{H}_{0}$ & $\mathrm{H}_{0}$ & $\mathrm{H}_{0}$ & $\mathrm{H}_{0}$ & $\mathrm{H}_{0}$ \\
\hline & $135^{\circ}$ & $\mathrm{H}_{0}$ & $\mathrm{H}_{0}$ & $\mathrm{H}_{0}$ & $\mathrm{H}_{0}$ & $\mathrm{H}_{0}$ & $\mathrm{H}_{0}$ & $\mathrm{H}_{0}$ \\
\hline \multirow{4}{*}{$\begin{array}{c}\text { Lock chain } \\
\text { vs. } \\
\text { "回" }\end{array}$} & $0^{\circ}$ & $\mathrm{H}_{0}$ & $\mathrm{H}_{0}$ & $\mathrm{H}_{0}$ & $\mathrm{H}_{0}$ & $\mathrm{H}_{0}$ & $\mathrm{H}_{1}$ & $\mathrm{H}_{0}$ \\
\hline & $45^{\circ}$ & $\mathrm{H}_{0}$ & $\mathrm{H}_{0}$ & $\mathrm{H}_{0}$ & $\mathrm{H}_{0}$ & $\mathrm{H}_{0}$ & $\mathrm{H}_{1}$ & $\mathrm{H}_{0}$ \\
\hline & $90^{\circ}$ & $\mathrm{H}_{0}$ & $\mathrm{H}_{0}$ & $\mathrm{H}_{0}$ & $\mathrm{H}_{0}$ & $\mathrm{H}_{0}$ & $\mathrm{H}_{1}$ & $\mathrm{H}_{1}$ \\
\hline & $135^{\circ}$ & $\mathrm{H}_{0}$ & $\mathrm{H}_{0}$ & $\mathrm{H}_{0}$ & $\mathrm{H}_{0}$ & $\mathrm{H}_{0}$ & $\mathrm{H}_{1}$ & $\mathrm{H}_{0}$ \\
\hline \multirow{4}{*}{$\begin{array}{c}\text { Turtle back } \\
\text { vs. } \\
\text { “回” }\end{array}$} & $0^{\circ}$ & $\mathrm{H}_{0}$ & $\mathrm{H}_{0}$ & $\mathrm{H}_{0}$ & $\mathrm{H}_{0}$ & $\mathrm{H}_{0}$ & $\mathrm{H}_{1}$ & $\mathrm{H}_{0}$ \\
\hline & $45^{\circ}$ & $\mathrm{H}_{0}$ & $\mathrm{H}_{0}$ & $\mathrm{H}_{0}$ & $\mathrm{H}_{0}$ & $\mathrm{H}_{0}$ & $\mathrm{H}_{1}$ & $\mathrm{H}_{0}$ \\
\hline & $90^{\circ}$ & $\mathrm{H}_{0}$ & $\mathrm{H}_{0}$ & $\mathrm{H}_{0}$ & $\mathrm{H}_{0}$ & $\mathrm{H}_{0}$ & $\mathrm{H}_{1}$ & $\mathrm{H}_{1}$ \\
\hline & $135^{\circ}$ & $\mathrm{H}_{0}$ & $\mathrm{H}_{0}$ & $\mathrm{H}_{0}$ & $\mathrm{H}_{0}$ & $\mathrm{H}_{0}$ & $\mathrm{H}_{0}$ & $\mathrm{H}_{0}$ \\
\hline
\end{tabular}

$\mathrm{H}_{0}$ : supports the hypothesis that the texture features between the two auspicious patterns are similar; $\mathrm{H}_{1}$ : supports the hypothesis that the texture features between the two auspicious patterns are dissimilar. Confidence level $\alpha: 0.05$.

\subsection{Similarity of an Auspicious Pattern between Any Two Surveyed Artists}

Figure 6 shows a diagram of master and apprentice relationships for the surveyed artists, who acquired more than 10 auspicious pattern images for the fish scales or turtle back patterns. Some of the artists shown in Figure 6 were not surveyed for this paper, but they are/were the teachers of the surveyed artists, and are necessary to display in the diagram of the master and apprentice relationships. Figure 6 illustrates that the surveyed artists can be approximately separated into two family genres, i.e., Y.-F. Chen and C.-Y. Pan. Indeed, C.-C. Liu not only apprenticed to his uncle (belonging to the family genre of Pan), but also learned from S.-Y. Chen (belonging to the family genre of Chen) and the other artists by observing their treatment skills with the door god paintings. Thus, the theory is that the painting style of C.-C. Liu should involve those of the two family genres. On the other hand, F.-T. Kuo (Chinese transliteration: 郭佛賜) and Y.-C. Chen (Chinese transliteration: 陳陽春) do not have any master and apprentice relationships with the other surveyed artists, including with one another. Therefore, the theory is that there should be a great difference in the painting styles of F.-T. Ku or Y.-C. Chen from the others, including one another.

The two-tailed $t$-test results for the similarities between any two surveyed artists fish scales and lock chain patterns in the four orientations are recorded in the symmetric matrices as shown in Tables 3 and 4, respectively. Excluding the diagonal elements of the matrices, each element uses a vector to record the two-tailed $t$-test result. In a vector of [], the elements express the acceptances of the hypotheses based on the co-occurrence features of ASM, CON, HOM, ENT, DIS, COR, and CLU in sequence, and the symbols of " 0 " and " 1 " indicate confirmation of the $\mathrm{H}_{0}$ and $\mathrm{H}_{1}$ hypotheses, respectively. 


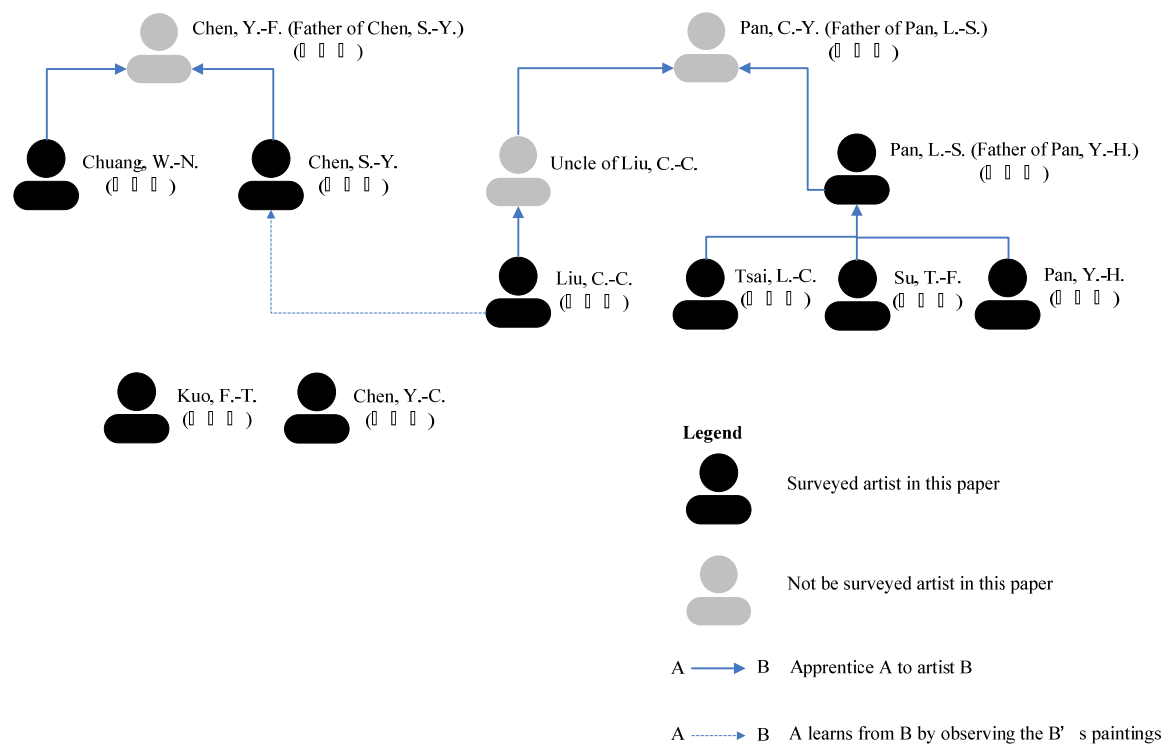

Figure 6. A diagram of master and apprentice relationships between the surveyed artists (black coloring) and their mentors (gray coloring).

Table 3. Two-tailed $t$-test results for similarity between any two surveyed artists' fish scales patterns in the orientations.

\begin{tabular}{|c|c|c|c|c|c|c|c|c|}
\hline Orientation & Artist & Liu, C.-C. & Kuo, F.-T. & Chen, Y.-C. & Pan, L.-S. & Tsai, L.-C. & Chen, S.-Y. & Pan, Y.-H. \\
\hline \multirow{7}{*}{$0^{\circ}$} & Liu, C.-C. & & {$[1,1,1,1,1,0,1]$} & {$[1,0,0,1,0,1,0]$} & {$[1,1,1,1,1,1,0]$} & {$[1,1,1,1,1,0,1]$} & {$[0,0,0,0,0,1,0]$} & {$[0,1,1,0,1,1,0]$} \\
\hline & Kuo, F.-T. & & & {$[1,1,1,1,1,1,0]$} & {$[1,1,1,1,1,1,1]$} & {$[0,0,0,0,0,1,0]$} & {$[1,0,1,1,1,1,0]$} & {$[1,1,1,1,1,1,0]$} \\
\hline & Chen, Y.-C. & & & & {$[1,1,1,1,1,1,1]$} & {$[1,1,1,1,1,0,1]$} & {$[0,0,0,0,0,0,0]$} & {$[1,1,1,1,1,1,0]$} \\
\hline & Pan, L.-S. & & & & & {$[1,1,1,1,1,1,1]$} & {$[1,1,1,1,1,1,0]$} & {$[1,1,0,1,0,1,1]$} \\
\hline & Tsai, L.-C. & & & & & & {$[1,0,1,1,0,0,0]$} & {$[1,1,1,1,1,1,1]$} \\
\hline & Chen, S.-Y. & & & & & & & {$[0,1,1,0,1,1,0]$} \\
\hline & Pan, Y.-H. & & & & & & & \\
\hline \multirow{7}{*}{$45^{\circ}$} & Liu, C.-C. & & {$[1,0,1,1,1,0,1]$} & {$[0,0,0,0,0,0,0]$} & {$[1,1,1,1,1,1,1]$} & {$[1,0,1,1,0,1,1]$} & {$[0,0,0,0,0,1,0]$} & {$[0,1,1,1,1,1,1]$} \\
\hline & Kuo, F.-T. & & & {$[1,1,1,1,1,0,1]$} & {$[1,1,1,1,1,1,1]$} & {$[0,0,0,0,0,0,0]$} & {$[1,0,1,1,1,0,0]$} & {$[1,1,1,1,1,1,1]$} \\
\hline & Chen, Y.-C. & & & & {$[1,1,1,1,1,1,1]$} & {$[1,1,1,1,1,0,1]$} & {$[0,0,0,0,0,0,0]$} & {$[1,1,1,1,1,1,1]$} \\
\hline & Pan, L.-S. & & & & & {$[1,1,1,1,1,0,1]$} & {$[1,1,1,1,1,0,1]$} & {$[1,0,0,1,0,1,1]$} \\
\hline & Tsai, L.-C. & & & & & & {$[1,0,0,1,0,0,0]$} & {$[1,1,1,1,1,1,1]$} \\
\hline & Chen, S.-Y. & & & & & & & {$[1,1,1,1,1,1,1]$} \\
\hline & Pan, Y.-H. & & & & & & & \\
\hline \multirow{7}{*}{$90^{\circ}$} & Liu, C.-C. & & {$[1,1,1,1,1,0,1]$} & {$[0,0,0,0,0,0,1]$} & {$[0,1,1,1,1,1,0]$} & {$[1,1,1,1,1,0,1]$} & {$[0,0,0,0,0,1,0]$} & {$[0,1,1,0,1,1,1]$} \\
\hline & Kuo, F.-T. & & & {$[1,1,1,1,1,0,1]$} & {$[1,1,1,1,1,1,1]$} & {$[0,0,0,0,0,0,0]$} & {$[1,1,1,1,1,1,1]$} & {$[1,1,1,1,1,1,0]$} \\
\hline & Chen, Y.-C. & & & & {$[1,1,1,1,1,1,1]$} & {$[1,1,1,1,1,1,1]$} & {$[0,0,0,0,0,1,0]$} & {$[0,1,1,0,1,1,1]$} \\
\hline & Pan, L.-S. & & & & & {$[1,1,1,1,1,1,1]$} & {$[0,1,1,0,1,1,0]$} & {$[1,1,0,1,0,1,1]$} \\
\hline & Tsai, L.-C. & & & & & & {$[1,1,1,1,1,0,1]$} & {$[1,1,1,1,1,1,0]$} \\
\hline & Chen, S.-Y. & & & & & & & {$[0,1,1,0,1,1,1]$} \\
\hline & Pan, Y.-H. & & & & & & & \\
\hline \multirow{7}{*}{$135^{\circ}$} & Liu, C.-C. & & {$[1,0,1,1,1,0,1]$} & {$[0,0,0,0,0,0,0]$} & {$[1,1,1,1,1,1,1]$} & {$[1,0,1,1,1,0,1]$} & {$[0,0,0,0,0,0,0]$} & {$[0,1,1,1,1,1,1]$} \\
\hline & Kuo, F.-T. & & & {$[1,1,1,1,1,0,1]$} & {$[1,1,1,1,1,1,1]$} & {$[0,0,0,0,0,1,0]$} & {$[1,0,1,1,1,0,0]$} & {$[1,1,1,1,1,1,1]$} \\
\hline & Chen, Y.-C. & & & & {$[1,1,1,1,1,0,1]$} & {$[1,1,1,1,1,0,1]$} & {$[0,0,0,0,0,0,0]$} & {$[1,1,1,1,1,1,1]$} \\
\hline & Pan, L.-S. & & & & & {$[1,1,1,1,1,1,1]$} & {$[1,1,1,1,1,0,1]$} & {$[1,0,0,1,0,1,1]$} \\
\hline & Tsai, L.-C. & & & & & & {$[1,0,1,1,0,0,0]$} & {$[1,1,1,1,1,1,1]$} \\
\hline & Chen, S.-Y. & & & & & & & {$[1,1,1,1,1,1,1]$} \\
\hline & Pan, Y.-H. & & & & & & & \\
\hline
\end{tabular}

Confidence level $\alpha$ : 0.1. The elements in a vector of [] indicate the hypotheses supported based on the cooccurrence features of ASM, CON, HOM, ENT, DIS, COR, and CLU, in sequence, and " 0 " and " 1 " denote $\mathrm{H}_{0}$ and $\mathrm{H}_{1}$, respectively. 
Table 4. Two-tailed $t$-test results for similarity between any two surveyed artists' lock chain patterns in the orientations.

\begin{tabular}{|c|c|c|c|c|c|c|c|}
\hline Orientation & Artist & Liu, C.-C. & Su, T.-F. & Chen, Y.-C. & Pan, L.-S. & $\begin{array}{l}\text { Chuang, } \\
\text { W.-N. }\end{array}$ & Chen, S.-Y. \\
\hline $0^{\circ}$ & $\begin{array}{c}\text { Liu, C.-C. } \\
\text { Su, T.-F. } \\
\text { Chen, Y.-C. } \\
\text { Pan, L.-S. } \\
\text { Chuang, W.-N. } \\
\text { Chen, S.-Y. }\end{array}$ & & {$[1,0,1,1,1,0,1]$} & $\begin{array}{l}{[0,0,0,0,0,1,0]} \\
{[1,1,1,1,1,0,1]}\end{array}$ & $\begin{array}{l}{[1,1,1,1,1,1,0]} \\
{[1,1,1,1,1,1,1]} \\
{[1,1,1,1,1,1,0]}\end{array}$ & $\begin{array}{l}{[1,1,1,1,1,0,1]} \\
{[0,0,0,0,0,0,0]} \\
{[1,1,1,1,1,0,1]} \\
{[1,1,1,1,1,1,1]}\end{array}$ & $\begin{array}{l}{[0,0,0,0,0,1,0]} \\
{[1,0,1,1,1,0,1]} \\
{[0,0,0,0,0,0,0]} \\
{[1,1,1,1,1,1,1]} \\
{[1,0,1,1,1,0,1]}\end{array}$ \\
\hline $45^{\circ}$ & $\begin{array}{c}\text { Liu, C.-C. } \\
\text { Su, T.-F. } \\
\text { Chen, Y.-C. } \\
\text { Pan, L.-S. } \\
\text { Chuang, W.-N. } \\
\text { Chen, S.-Y. }\end{array}$ & & {$[1,0,0,1,0,0,0]$} & $\begin{array}{l}{[0,0,0,0,0,1,0]} \\
{[0,0,0,0,0,0,0]}\end{array}$ & $\begin{array}{l}{[1,1,1,1,1,1,1]} \\
{[1,1,1,1,1,0,1]} \\
{[1,1,1,1,1,0,1]}\end{array}$ & $\begin{array}{l}{[1,0,1,1,1,1,1]} \\
{[0,0,0,0,0,0,0]} \\
{[1,1,1,1,1,0,1]} \\
{[1,1,1,1,1,0,1]}\end{array}$ & $\begin{array}{l}{[0,0,0,0,0,1,0]} \\
{[0,0,0,0,0,0,0]} \\
{[0,0,0,0,0,0,0]} \\
{[1,1,1,1,1,0,1]} \\
{[1,0,0,0,0,0,0]}\end{array}$ \\
\hline $90^{\circ}$ & $\begin{array}{c}\text { Liu, C.-C. } \\
\text { Su, T.-F. } \\
\text { Chen, Y.-C. } \\
\text { Pan, L.-S. } \\
\text { Chuang, W.-N. } \\
\text { Chen, S.-Y. }\end{array}$ & & {$[1,1,1,1,1,0,1]$} & $\begin{array}{l}{[0,0,0,0,0,1,0]} \\
{[1,1,1,1,1,1,1]}\end{array}$ & $\begin{array}{l}{[1,1,1,1,1,1,0]} \\
{[1,1,1,1,1,1,1]} \\
{[1,1,1,1,1,1,0]}\end{array}$ & $\begin{array}{l}1,1,1,1,1,0,1] \\
{[0,0,0,0,0,0,0]} \\
{[1,1,1,1,1,1,1]} \\
{[1,1,1,1,1,1,1]}\end{array}$ & $\begin{array}{l}{[1,0,0,1,0,1,1]} \\
{[0,1,1,0,1,0,0]} \\
{[0,0,0,0,0,1,1]} \\
{[1,1,1,1,1,1,1]} \\
{[1,1,1,1,1,1,0]}\end{array}$ \\
\hline $135^{\circ}$ & $\begin{array}{c}\text { Liu, C.-C. } \\
\text { Su, T.-F. } \\
\text { Chen, Y.-C. } \\
\text { Pan, L.-S. } \\
\text { Chuang, W.-N. } \\
\text { Chen, S.-Y. }\end{array}$ & & {$[1,0,0,1,0,0,0]$} & $\begin{array}{l}{[0,0,0,0,0,0,0]} \\
{[0,0,0,0,0,0,0]}\end{array}$ & $\begin{array}{l}{[1,1,1,1,1,1,1]} \\
{[1,1,1,1,1,0,1]} \\
{[1,1,1,1,1,0,1]}\end{array}$ & $\begin{array}{l}{[1,1,1,1,1,0,1]} \\
{[0,0,0,0,0,0,0]} \\
{[1,1,1,1,1,0,1]} \\
{[1,1,1,1,1,0,1]}\end{array}$ & $\begin{array}{l}{[0,0,0,0,0,0,0]} \\
{[0,0,0,0,0,0,0]} \\
{[0,0,0,0,0,0,0]} \\
{[1,1,1,1,1,0,1]} \\
{[1,0,0,0,0,0,0]}\end{array}$ \\
\hline
\end{tabular}

Confidence level $\alpha: 0.1$. The elements in a vector of [] indicate the hypotheses supported based on the cooccurrence features of ASM, CON, HOM, ENT, DIS, COR, and CLU, in sequence, and " 0 " and " 1 " denote $\mathrm{H}_{0}$ and $\mathrm{H}_{1}$, respectively.

Based on the diagram of the master and apprentice relationships in Figure 6, the two-tailed $t$-test results in Tables 3 and 4 are discussed. Most of the two-tailed $t$-test results successfully indicate the differences in the painting styles between the two main family genres of Chen and Pan. For instance, Table 3 demonstrates that the painting style of S.-Y. Chen is significantly different from those of L.-S. Pan, L.-C. Tsai, and Y.-H. Pan. Moreover, Table 4 shows that the painting style of L.-S. Pan is robustly different from those of S.-Y. Chen and W.-N. Chuang. However, there is an unreasonable result of recognizing the painting styles between the two main family genres of Chen and Pan as W.-N. Chuang versus T.-F. Su (see Table 4); W.-N. Chang and T.-F. Su belong to the family genres of Chen and Pan, respectively, but the two-tailed $t$-test result indicates that they have a robust similarity in painting style.

In the same family genre, this paper notes that the painting styles of the direct relatives of master and apprentice—such as L.-S. Pan versus L.-C. Tsai, T.-F. Su, or Y.-H. Pan—should be extremely similar. Unfortunately, Tables 3 and 4 cannot effectively demonstrate that a similar painting style exists among the above direct relatives of master and apprentice. For the collateral relatives of apprentices, Table 4 shows in the family genre of Chen that the painting styles of S.-Y. Chen and W.-N. Chuang have higher textural similarity in the double-diagonal orientations than in the horizontal and vertical orientations. The above characteristic also exists in the family genre of Pan, such as with C.-C. Liu versus T.-F. Su, but excludes L.-C. Tsai versus C.-C. Liu or Y.-H. Pan.

For the fish scales pattern, the co-occurrence features of ASM, HOM, ENT, and DIS have higher applicability to demonstrate the master and apprentice relationships in Figure 6 than the others. Based on the four above co-occurrence features, however, L.-C. Tsai and Y.-C. Chen, relative to the other surveyed artists in Table 3, seem to obtain fewer 
reasonable demonstrations of master and apprentice relationships between them and the other artists. For the lock chain pattern, except for COR, the other co-occurrence features have approximate applicability to demonstrate the master and apprentice relationships. Furthermore, among the surveyed artists in Table 4, T.-F. Su shows the fewest reasonable demonstrations of master and apprentice relationships between him and the other artists. Consequently, in this paper the three artists L.-C. Tsai, Y.-C. Chen, and T.-F. Su were excluded from the following two-tailed $t$-test to observe the similarity of the fish scales and lock chain patterns between the surveyed and unknown artists. Moreover, ASM, HOM, ENT, and DIS were considered in the two-tailed $t$-test based on the fish scales pattern, and in addition to the four above co-occurrence features, CON and CLU were considered in the test based on the lock chain pattern.

\subsection{Similarity of Auspicious Patterns between Surveyed and Unknown Artists}

The two-tailed $t$-test was also used to assist in the painting style recognition of the unknown artists' door god paintings in Kinmen. If a robust similarity of an auspicious pattern between the surveyed and unknown artists is obtained, this suggests that the door god paintings of the unknown artist(s) could be restored by referring to the painting style of the surveyed artist. Tables 5 and 6 show the two-tailed $t$-test results for the similarities of the fish scales and lock chain patterns between the surveyed and unknown artists, respectively, and demonstrate that F.-T. Kuo and W.-N. Chuang have the most similar painting styles to the unknown artists' fish scales and lock chain patterns, respectively.

To further observe the painting styles of each surveyed artist, we performed an interquartile range calculation for the co-occurrence features extracted from the acquired auspicious pattern images. Therefore, one co-occurrence feature in the four orientations can calculate four medians via the interquartile range analysis, and this paper adopts a mean value of the four medians of the co-occurrence feature to describe the painting style. The charts shown as Figure 7 plot the means of the medians of the extracted co-occurrence feature values for the surveyed artists' fish scales and lock chain patterns, respectively. By discussing Figure 7, the painting styles of the fish scales and lock chain patterns of the unknown artists in Kinmen could be surmised.

Table 5. Two-tailed $t$-test results for similarity between surveyed and unknown artists' fish scales patterns in the orientations.

\begin{tabular}{ccccccc}
\hline Orientation & Artist & Liu, C.-C. & Kuo, F.-T. & Pan, L.-S. & Chen, S.-Y. & Pan, Y.-H. \\
\hline $0^{\circ}$ & & {$[1,1,1,1]$} & {$[0,0,0,0]$} & {$[1,1,1,1]$} & {$[1,1,1,1]$} & {$[1,1,1,1]$} \\
$45^{\circ}$ & \multirow{2}{*}{ Unknown } & {$[1,1,1,1]$} & {$[0,0,0,0]$} & {$[1,1,1,1]$} & {$[1,1,1,1]$} & {$[1,1,1,1]$} \\
$90^{\circ}$ & & {$[1,1,1,1]$} & {$[1,0,0,0]$} & {$[1,1,1,1]$} & {$[1,1,1,1]$} & {$[1,1,1,1]$} \\
$135^{\circ}$ & & {$[1,1,1,1]$} & {$[0,0,0,0]$} & {$[1,1,1,1]$} & {$[1,1,1,1]$} & {$[1,1,1,1]$} \\
\hline
\end{tabular}

Confidence level $\alpha$ : 0.1. The elements in a vector of [] indicate the hypotheses supported based on the co-occurrence features of ASM, HOM, ENT, and DIS, in sequence, and " 0 " and "1" denote $\mathrm{H}_{0}$ and $\mathrm{H}_{1}$, respectively.

Table 6. Two-tailed $t$-test results for similarity between surveyed and unknown artists' lock chain patterns in the orientations.

\begin{tabular}{cccccc}
\hline Orientation & Artist & Liu, C.-C. & Pan, L.-S. & Chuang, W.-N. & Chen, S.-Y. \\
\hline $0^{\circ}$ & & {$[1,1,1,1,1,1]$} & {$[1,1,1,1,1,1]$} & {$[0,0,0,0,0,0]$} & {$[1,1,1,1,1,0]$} \\
$45^{\circ}$ & \multirow{3}{*}{ Unknown } & {$[1,1,1,1,1,1]$} & {$[1,1,1,1,1,1]$} & {$[0,1,1,0,1,0]$} & {$[1,1,1,1,1,1]$} \\
$90^{\circ}$ & & {$[1,1,1,1,1,1]$} & {$[1,1,1,1,1,1]$} & {$[0,0,0,0,0,0]$} & {$[0,1,1,0,1,1]$} \\
$135^{\circ}$ & & {$[1,1,1,1,1,1]$} & {$[1,1,1,1,1,1]$} & {$[0,1,0,0,1,0]$} & {$[1,1,1,1,1,1]$} \\
\hline
\end{tabular}

Confidence level $\alpha$ : 0.1. The elements in a vector of [] indicate the hypotheses supported based on the cooccurrence features of ASM, CON, HOM, ENT, DIS, and CLU, in sequence, and " 0 " and " 1 " denote $\mathrm{H}_{0}$ and $\mathrm{H}_{1}$, respectively. 

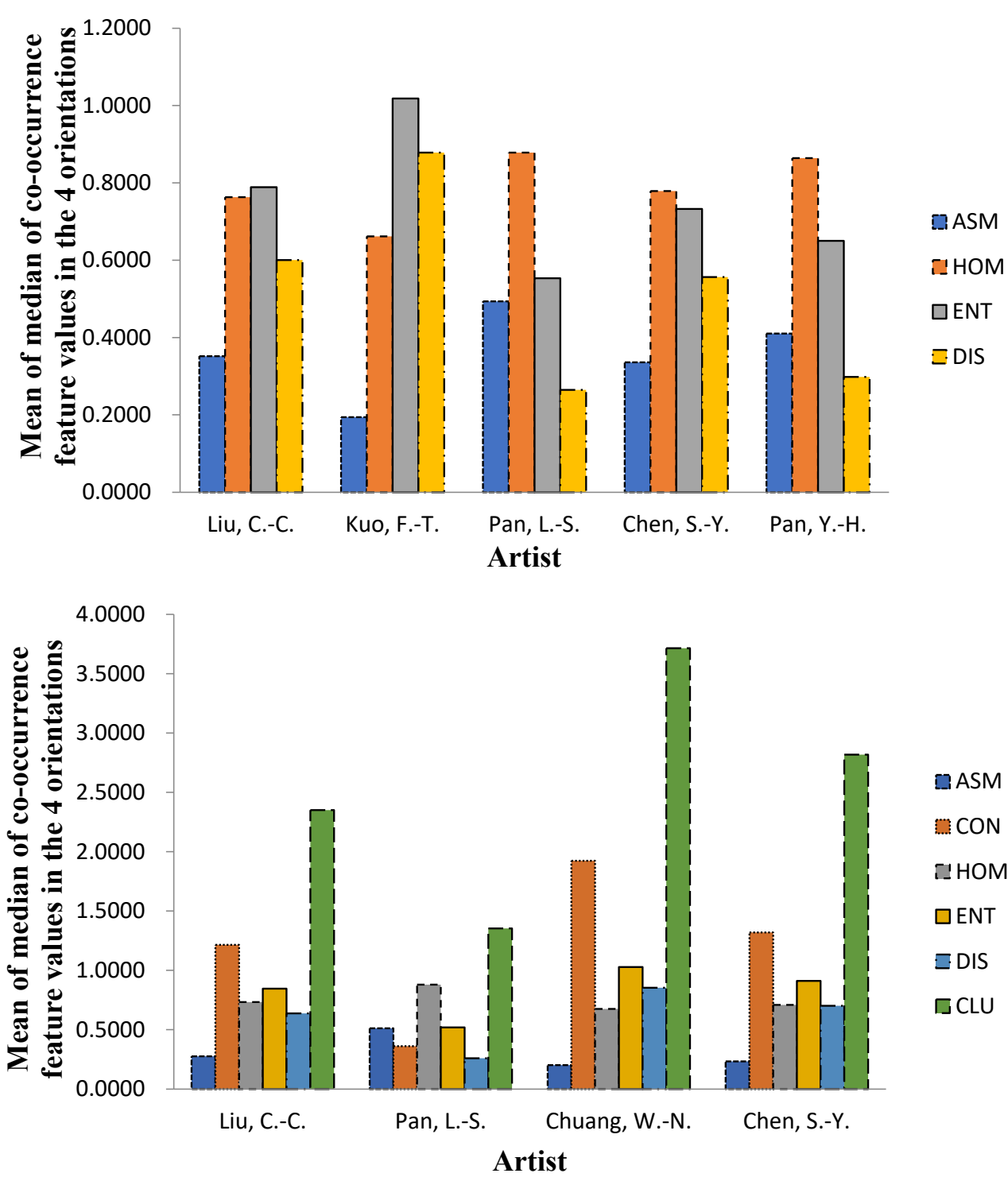

Figure 7. Means of medians of co-occurrence feature values in four orientations extracted from acquired auspicious pattern images of surveyed artists: fish scales pattern (upper chart); lock chain pattern (lower chart).

The upper chart of Figure 7 shows that F.-T. Kuo's fish scales patterns have lower ASM and HOM and higher ENT and DIS than those of the other surveyed artists. The lower ASM and HOM mean that the acquired fish scales pattern images of F.-T. Kuo exhibit lower images constancy, leading to a higher image contrast. Based on the higher ENT and DIS, this paper finds that F.-T. Kuo's fish scales patterns (or the unknown artists' fish scales patterns in Kinmen) have higher textural complexity and higher hue gradient than those of the other surveyed artists.

In addition to ASM, HOM, ENT, and DIS, CON and CLU can help describe the painting style of W.-N. Chuang's lock chain patterns (or the unknown artists' lock chain patterns in Kinmen). The lower chart of Figure 7 shows that W.-N. Chuang's lock chain patterns also have lower ASM and HOM and higher ENT and DIS than those of the other surveyed artists. Because the representation of $\mathrm{HOM}$ is contrary to that of $\mathrm{CON}$, the lower chart illustrates that W.-N. Chuang's lock chain patterns have higher CON than those of the other surveyed artists. The lower chart also shows that W.-N. Chuang's lock chain patterns have the highest CLU among the surveyed artists. Thus, this result indirectly explains why 
the unknown artists' lock chain patterns in Kinmen have higher textural clustering than the surveyed artists.

From the above discussion, this paper finds that there should be a similar door god painting style between F.-T. Kuo and W.-N. Chuang, because both of their auspicious patterns have the same characteristics of lower ASM and HOM and higher ENT and DIS. Thus, the door god paintings in Kinmen could be restored by referring to the painting styles of F.-T. Kuo or W.-N. Chuang.

\section{Conclusions}

Based on a two-level two-dimensional DWT and gray-level co-occurrence matrix calculation, this research proposes a texture feature extraction procedure and, coupled with a two-tailed $t$-test to analyze the door god painting styles, demonstrates the master and apprentice relationships between the surveyed artists so as to recognize unknown artists painting styles. In total, 52 temples in Taiwan were visited to acquire 453 images for the auspicious patterns—including fish scales, lock chain, turtle back, and “回"一on the armor of door god warriors created by the surveyed artists. Additionally, 12 auspicious pattern images of unknown artists' door god paintings in Kinmen, which is an outlying island of Taiwan, were also acquired.

In the door god painting style analysis, the result indicates that all four auspicious patterns have texture symmetry in the double-diagonal orientations. The texture of the fish scales patterns is more constant (i.e., lower contrast) than that of the other patterns. For any auspicious pattern, the textural contrast in the double-diagonal orientations is higher than those in the horizontal or vertical orientations and, among the four auspicious patterns, the turtle back pattern usually has the highest textural contrast. Except in the vertical orientation, the turtle back pattern has the highest textural complexity. In the vertical orientation, the highest textural complexity exists in the "回" pattern. Generally, there is the most textural difference between the fish scales and lock chain patterns, and the most textural similarity between the lock chain and turtle back patterns. The analysis herein also successfully demonstrates the interrelationships between the seven co-occurrence features.

The results of our analysis effectively demonstrate the differences in the painting styles between the family genres of Chen and Pan. In a family genre, however, the results of our analysis fail to indicate that artists with a direct relationship of master and apprentice are expected to have a similar painting style. As for the collateral relatives of apprentices, our findings confirm that the artists' auspicious patterns seem to have higher textural similarity in the double-diagonal orientations than in the horizontal and vertical orientations. Through the two-tailed $t$-test, based on the fish scales pattern, we found that the co-occurrence features of ASM, HOM, ENT, and DIS are useful to demonstrate the apprentice relationships between the five artists of C.-C. Liu et al. Based on the lock chain pattern, except for $\mathrm{COR}$, the other six co-occurrence features are useful to demonstrate the apprentice relationships between the four artists of C.-C. Liu et al.

Among the surveyed artists, F.-T. Kuo and W.-N. Chuang have the most similar painting styles to the unknown artists' fish scales and lock chain patterns, respectively. Thus, the door god paintings in Kinmen could be restored by referring to the painting styles of F.-T. Kuo or W.-N. Chuang. According to the analyzed painting styles of Kuo and Chuang, this paper surmises the painting styles of unknown artists in Kinmen, indicating that the unknown artists' fish scales patterns exhibit higher textural contrast, textural complexity, and hue gradient than those of the surveyed artists. Furthermore, the unknown artists' lock chain patterns also have higher textural contrast and clustering than those of the surveyed artists.

The hypothesis testing method can currently determine the useful co-occurrence features for recognizing the unknown artists' painting styles. In the future, the useful co-occurrence features will be input into neural networks in order to recognize the style of every single door god painting. We also believe that deep learning convolutional neural 
networks based on the human visual system would be useful in recognizing the style of every single door god painting.

Supplementary Materials: The following supporting information can be downloaded at: https: / / drive.google.com/file/d/1ax76s22qelbdEmsi5ILhCKe3HlrvhAoP/view?usp=sharing (accessed on 1 December 2021).

Author Contributions: Conceptualization, T.-C.S. and T.-C.W.; methodology, T.-C.S.; software, T.-C.S. and M.-H.W.; validation, T.-C.S. and T.-C.W.; formal analysis, M.-H.W. and C.-W.W.; investigation, T.-C.S., M.-H.W. and C.-W.W.; data curation, M.-H.W.; writing - original draft preparation, T.-C.S.; writing - review and editing, T.-C.S. and T.-C.W.; project administration, T.-C.S.; funding acquisition, T.-C.S. All authors have read and agreed to the published version of the manuscript.

Funding: This research was funded by the Ministry of Science and Technology, Taiwan, grant number MOST 108-2410-H-507-013-MY2. The APC was funded by the Ministry of Science and Technology, Taiwan.

Conflicts of Interest: The authors declare no conflict of interest.

\section{References}

1. Wu, S. A Report of Restoration Project for Tsao-Ju Tsai's Door God Paintings in the Pei Tian Temple, Chiayi, Taiwan; Tainan National University of the Arts: Tainan, Taiwan, 2016. (In Chinese)

2. Hung, H.-S. A study on architecture Du Tou painting of Li Jin Cyuan and his apprentices. Collect. Pap. Arts Res. 2013, 20-21, 21-47. (In Chinese)

3. Wang, X.-G. Analysis of the door-god painting pattern in Zhangzhou. J. Jimei Univ. 2011, 14, 16-22. (In Chinese)

4. Lee, Y.-Y. Appreciation of painted door gods and armours in temples. Art Apprec. 2009, 5, 15-20. (In Chinese)

5. Kawanaka, H.; Kosaka, S.; Iwahori, Y.; Sugiyama, S. Image reproduction based on texture image extension with traced drawing for heavy damaged mural painting. Procedia Comput. Sci. 2013, 22, 968-975. [CrossRef]

6. Ortiz, R.; Ortiz, P.; Colao, F.; Fantoni, R.; Gómez-Morón, M.A.; Vázquez, M.A. Laser spectroscopy and imaging applications for the study of cultural heritage murals. Constr. Build. Mater. 2015, 98, 35-43. [CrossRef]

7. Pan, N.; Hou, M.; Lv, S.; Hu, Y.; Zhao, X.; Ma, Q.; Li, S.; Shaker, A. Extracting faded mural patterns based on the combination of spatial-spectral feature of hyperspectral image. J. Cult. Herit. 2017, 27, 80-87. [CrossRef]

8. Lillesand, T.M.; Kiefer, R.W.; Chipman, J.W. Remote Sensing and Image Interpretation, 6th ed.; John Wiley \& Sons, Inc.: Hoboken, NJ, USA, 2008.

9. Cai, Y.; Siegel, M. Texture Characterization of the Visual Appearance of Paintings. In Proceedings of the 19th IEEE Instrumentation and Measurement Technology Conference, Anchorage, AK, USA, 21-23 May 2002.

10. El-Rifai, I.; Mahgoub, H.; Ide-Ektessabi, A. Multi-spectral Imaging System (IWN) for the Digitization and Investigation of Cultural Heritage. In Proceedings of the Part I of EuroMed: Euro-Mediterranean Conference, Nicosia, Cyprus, 31 October-5 November 2016.

11. Ricca, M.; Alberghina, M.F.; Randazzo, L.; Schiavone, S.; Donato, A.; Albanese, M.P.; La Russa, M.F. A combined non-destructive and micro-destructive approach to solving the forensic problems in the field of cultural heritage: Two case studies. Appl. Sci. 2021, 11, 6951. [CrossRef]

12. Zujovic, J.; Gandy, L.; Friedman, S.; Pardo, B.; Pappas, T.N. Classifying Paintings by Artistic Genre: An Analysis of Features \& Classifiers. In Proceedings of the IEEE International Workshop on Multimedia Signal Processing, Rio de Janeiro, Brazil, 5-7 October 2009.

13. Keshvari, S.; Chalechale, A. Classification of Iranian Paintings Using Texture Analysis. In Proceedings of the 2016 6th International Conference on Computer and Knowledge Engineering (ICCKE), Mashhad, Iran, 20-20 October 2016.

14. Lee, S.-G.; Cha, E.-Y. Style classification and visualization of art painting's genre using self-organizing maps. Hum.-Cent. Comput. Inf. Sci. 2016, 6, 7. [CrossRef]

15. Gultepe, E.; Conturo, T.E.; Makrehchi, M. Predicting and grouping digitized paintings by style using unsupervised feature learning. J. Cult. Herit. 2018, 31, 13-23. [CrossRef]

16. Narag, M.J.G.; Soriano, M.N. Identifying the Painter Using Texture Features and Machine Learning Algorithms. In Proceedings of the 3rd International Conference on Cryptography, Security and Privacy, Kuala Lumpur, Malaysia, 19-21 January 2019.

17. Crupi, V.; Fazio, B.; Fiocco, G.; Galli, G.; La Russa, M.F.; Licchelli, M.; Majolino, D.; Malagodi, M.; Ricca, M.; Ruffolo, S.A.; et al. Multi-analytical study of Roman frescoes from Villa dei Quintili (Rome, Italy). J. Archaeol. Sci. Rep. 2018, 21, 422-432. [CrossRef]

18. Lu, G.; Gao, Z.; Qin, D.; Zhao, X.; Liu, M. Content-based Identifying and Classifying Traditional Chinese Painting Images. In Proceedings of the 2008 Congress on Image and Signal Processing, Sanya, China, 27-30 May 2008.

19. Lyu, S.; Rockmore, D.; Farid, H. A digital technique for art authentication. Proc. Natl. Acad. Sci. USA 2004, 101, 17006-17010. [CrossRef] [PubMed] 
20. Cetinic, E.; Grgic, S. Automated Painter Recognition based on Image Feature Extraction. In Proceedings of the International Symposium on Electronics in Marine (ELMAR-2013), Zadar, Croatia, 25-27 September 2013.

21. Johnson, C.R.; Hendriks, E.; Berezhnoy, I.J.; Brevdo, E.; Hughes, S.M.; Daubechies, I.; Li, J.; Postma, E.; Wang, J.Z. Image Processing for artist identification. IEEE Signal Process. Mag. 2008, 25, 37-48. [CrossRef]

22. Jafarpour, S.; Polatkan, G.; Brevdo, E.; Hughes, S.; Brasoveanu, A.; Daubechies, I. Stylistic Analysis of Paintings Using Wavelets and Machine Learning. In Proceedings of the 2009 17th European Signal Processing Conference, Glasgow, UK, 24-28 August 2009.

23. Ji, Y.; Sun, L.; Li, Y.; Ye, D. Detection of bruised potatoes using hyperspectral imaging technique based on discrete wavelet transform. Infrared Phys. Technol. 2019, 103, 103054. [CrossRef]

24. Ghahfarrokhi, S.S.; Khodadadi, H. Human brain tumor diagnosis using the combination of the complexity measures and texture features through magnetic resonance image. Biomed. Signal Process Control 2020, 61, 102025. [CrossRef]

25. Lee, Y.-H. Amazing Gods on Doors: Door God Paintings in Taiwan from 1821 to 1970; Bureau of Cultural Heritage, Ministry of Culture (BOCH): Taichung, Taiwan, 2013. (In Chinese)

26. Kang, N.-H. Catalogue of Door God Paintings in Taiwan; Owl Publishing House Co., Ltd.: Taipei, Taiwan, 2012. (In Chinese)

27. Lu, W.; Gao, X.; Tao, D.; Li, X. A wavelet-based image quality assessment method. Int. J. Wavelets Multiresolution Inf. Process. 2008, 6, 541-551. [CrossRef]

28. Yang, M.-D.; Su, T.-C.; Pan, N.-F.; Liu, P. Feature extraction of sewer pipe defects using wavelet transform and co-occurrence matrix. Int. J. Wavelets Multiresolution Inf. Process. 2011, 9, 211-225. [CrossRef]

29. Beura, S.; Majhi, B.; Dash, R. Mammogram classification using two dimensional discrete wavelet transform and gray-level co-occurrence matrix for detection of breast cancer. Neurocomputing 2015, 154, 1-14. [CrossRef]

30. Sudarshan, V.K.; Ng, E.Y.K.; Acharya, U.R.; Chou, S.M.; Tan, R.S.; Ghista, D.N. Computer-aided diagnosis of Myocardial Infarction using ultrasound images with DWT, GLCM and HOS methods: A comparative study. Comput. Biol. Med. 2015, 62, 86-93.

31. Yang, D.-W.; Wu, H. Three-dimensional temperature uniformity assessment based on gray level co-occurrence matrix. Appl. Therm. Eng. 2016, 108, 689-696. [CrossRef]

32. Canty, M.J. Image Analysis, Classification, and Change Detection in Remote Sensing with Algorithms for ENVI/IDL, 2nd ed.; CRC Press, Taylor \& Francis Group: Boca Raton, FL, USA, 2010.

33. Yang, M.-D.; Su, T.-C. Automated diagnosis of sewer pipe defects based on machine learning approaches. Expert Syst. Appl. 2008, 35, 1327-1337. [CrossRef]

34. Arebey, M.; Hannan, M.A.; Begum, R.A.; Basri, H. Solid waste bin level detection using gray level co-occurrence matrix feature extraction approach. J. Environ. Manag. 2012, 104, 9-18. [CrossRef] [PubMed]

35. O'Byrne, M.; Ghosh, B.; Pakrashi, V.; Schoefs, F. Texture Analysis based Detection and Classification of Surface Features on Ageing Infrastructure Elements. In Proceedings of the Bridge and Concrete Research in Ireland Conference, Dublin, Ireland, 6-7 September 2012.

36. Fu, K.-L.; Chen, C.-T.; Chen, S.-C. Texture analysis on SPOT images for detecting illegal use of regulated slopeland. J. Soil Water Conserv. 2004, 36, 201-214. (In Chinese)

37. National Institute of Standards and Technology (NIST). SEMATECH e-Handbook of Statistical Methods, Department of Commerce, US. Available online: https:/ /itl.nist.gov/div898/handbook/prc/section2/prc222.htm (accessed on 16 March 2021). 